\title{
Selection, Heterogeneity and the Gender Wage Gap*
}

\author{
Cecilia Machado ${ }^{\dagger}$
}

December 28, 2011

\begin{abstract}
Usual estimates of the female-male wage gap may be biased because female selection could be different in different parts of the labor market. This paper proposes an estimator for the wage gap in models with unobserved heterogeneity in the selection rule. It applies to the subpopulation of "always employed" women, which is similar to men in labor force attachment. Using CPS data from 1976 to 2005, I show that the gap has narrowed substantially from a -.521 to a -.263 log wage points. In the presence of heterogeneity, focusing on the proposed estimator is less distorting than usual selection corrections.
\end{abstract}

JEL: J31, J16, J24

Keywords: Selection, Gender Wage Gap

\footnotetext{
${ }^{*}$ I thank Douglas Almond, Janet Currie, Lena Edlund and Edward Vytlacil for advice and continuous support, and Joshua Angrist, Tiago Berriel, David Card, Yinghua He, James Heckman, Mariesa Herrmann, Bo Honoré, Lawrence Katz, Thomas Lemieux, Dennis Kristensen, David Lee, Bentley MacLeod, Marcelo Moreira, Casey Mulligan, Derek Neal, Cristian Pop-Eleches, Ricardo Reis, Yona Rubinstein, Johannes Schmieder, Jeffrey Smith, Till von Wachter, Reed Walker, and participants at the 2009 NBER Labor Studies Fall Meeting and at the Columbia Applied Micro Colloquium, Applied Micro Workshop and Econometrics Lunch, as well as participants in seminars and conferences, for useful discussions and comments. All errors are my own.

${ }^{\dagger}$ Getulio Vargas Foundation, EPGE. E-mail: machadoc@gmail.com
} 


\section{Introduction}

The narrowing of the gender wage gap in recent decades has been one of the most striking changes in the US labor market. Whereas in 1979 the US gender log wage differential was -.459, it shrank to -.227 in 1998 [Blau and Kahn, 2006]. Those estimates, however, may be biased by selection, since observed wages are sensitive to the characteristics of the individuals who opt into employment. In the US, the missing wage is a quite severe problem, as female full-time participation, albeit increasing, still averages just 50\% in recent years.

Correction methods for the selection problem date back to Gronau [1974] and Heckman [1974]. Recently, non-parametric bounds estimators of wage distribution parameters have been proposed under an alternative set of theoretical restrictions [Manski, 1990]. Surprisingly, the two approaches have arrived to starkly different conclusions about the evolution of the gender wage gap.

Mulligan and Rubinstein [2008], using a parametric selection model (among other methods), found no reduction in the gender gap in the US: their selection-corrected measure has remained stable at around -.338 since the 1970s. They find that selection into employment has switched from negative to positive, with observed gains masking important changes in the composition of the workforce. In contrast, Blundell et al. [2007] use bounding procedures and find an improvement in the wage gap in the UK from 1978 to 1998: a substantial change that ranges from .23 to .28 log points. A key assumption in their bounding procedure is the imposition of a positive selection rule, as the estimated change in the gap becomes uninformative once this assumption is relaxed.

The stance taken on the self-selection process is critical because female non-participation remains high. In the case of parametric selection models, a monolithic rule, which does not vary with other unmeasured characteristics of women, is implicitly assumed. In the case of non-parametric bounds, the sign of average selection is generally imposed.

When it comes to female wages and employment decisions, however, it is questionable

whether a unique or "homogeneous" selection mechanism can be assumed, or if the sign of the average selection effect is a priori known. While positive selection is the gold standard 
in traditional labor supply models, negative selection is also plausible for women: if couples match based on skills and out-of-work income rises with skills, one might conjecture that the employment decision of high skilled women reflects high reservation wages, while for low skilled women low potential earnings may be more important [Blundell et al., 2007]. And if both positive and negative selection rules co-exist in different parts of the labor market, it is unclear which selection mechanism dominates.

Neal [2004] documents heterogeneity in female selection by race: while black women were positively selected into work, white women were negatively selected. He finds that the employment decision of black women likely reflected low market wages, as non-working black women were generally under government assistance programs. White women's decision, on the contrary, likely reflected high reservation wages, as non-working white women were more likely to be married and have high household income. More generally, heterogeneity in selection can also depend on unobserved characteristics, such as spouse quality: the women with high spouse quality would be under a negative selection rule and vice-versa.

This paper departs from the existing approaches when differing selection rules co-exist, and the average sign of the selection effect is unknown. Specifically, I consider the case in which the heterogeneous rules depend on the same unobservables that govern self-selection.

I first generate an example with simulated data illustrating the core features of a labor supply model with unobserved heterogeneous selection rules. Under that example, I show that both the parametric selection model and the non-parametric bounds that sign the average selection by assumption fail to recover meaningful information on wages. However, under the same example, and more generally, under models that satisfy some instrumental variable (IV) conditions, a local measure of wages can still be recovered. Technically, the IV conditions are the same used to identify local average treatment effects in treatment effect models [Imbens and Angrist, 1994]: the existence of an instrument that is excluded from the wage equation and that shifts employment in the same direction for all individuals. The local measure of wages is recovered for the "always employed," drawing analogy to the "always takers" in treatment effect models [Angrist et al., 1996]. This subpopulation corresponds to individuals who participate in the labor market regardless of the value of the instrument. 
In the case of the gender wage gap, the "always employed" women may be a particularly relevant subpopulation to compare to men, as male labor force attachment is high and stable.

Using the Current Population Survey (CPS) data, and the presence of a child younger than six as the instrument for female employment, I estimate an improvement in the US gender gap for the group of women that work regardless of their fertility outcome. From 1976 to 2005 , the gender wage gap is reduced by .258 log wage points, a more than twofold improvement, from -.521 to -.263 points. In the same data, I also replicate the finding in Mulligan and Rubinstein [2008] and in Blundell et al. [2007], showing that the methods, rather than differences in the sample or in the choice of the instrument, are the driving force for the disparate results. As unobserved heterogeneity in selection is a relevant feature of female employment decisions, the estimator proposed in this paper constitutes an alternative parameter to be incorporated in studies of the gender wage gap.

The results are maintained under a series of robustness exercises, such as using alternative covariate controls, accounting for male selection and redefining the instrument by different ages of the young child present. Using a short panel data, I am able to conclude that the falling gender wage gap is likely due to reduced discrimination, rather than changes in the composition of the "always employed" population over the years. Finally, following Angrist et al. [1996], I assess the bias of the estimator when the identifying assumptions fail, and show that relaxing some of them yield qualitatively similar results.

This paper is organized as follows. The next section outlines the selection problem with missing outcomes, summarizes the existing literature, and provides an example of unobserved heterogeneity in the selection. Section 3 identifies the class of models, with arbitrary heterogeneity in selection, for which a local measure of potential wages can be recovered. Section 4 presents the baseline estimates and Section 5 contains the robustness exercises. A discussion on the validity of the assumptions necessary to identify the local gender gap is found in Section 6. Section 7 concludes. 


\section{Selection with Missing Outcomes and Heterogeneity}

\subsection{The Selection Problem}

Let $\mathcal{Y}$ denote the potential wages received by individuals in the market place and $Y$ the observed wages. The selection problem arises because $Y=\mathcal{Y}$ only for those found to be employed. Since individuals who choose employment are plausibly different from the ones who do not, the observed distribution of wages does not generalize to the entire population. Thus, a simple OLS regression of observed wages on a gender dummy will mask selection effects in both the male and female population.

How big is the selection problem? Denote by $E \in\{0,1\}$ the employment status and $G \in\{0,1\}$ the gender indicator, with $G=1$ for women. Conditional on covariates $X$, the unobserved mean of potential wages can be decomposed as:

$$
\mathrm{E}(\mathcal{Y} \mid X, G)=\mathrm{E}(Y \mid E=1, X, G) \operatorname{Pr}(E=1 \mid X, G)+\underbrace{\mathrm{E}(\mathcal{Y} \mid E=0, X, G)}_{\text {selection effect }} \underbrace{\operatorname{Pr}(E=0 \mid X, G)}_{\text {non-participation effect }}
$$

In words, the parameter of interest $\mathrm{E}(\mathcal{Y} \mid X, G)$ is a weighted average of wages among participants and non-participants, and the unobservability of $\mathrm{E}(\mathcal{Y} \mid E=0, X, G)$ poses the main challenge in any estimation strategy.

If $\mathrm{E}(Y \mid E=1, X, G) \geq \mathrm{E}(\mathcal{Y} \mid E=0, X, G)$, the selection effect is said to be positive, and individuals with higher wages are more likely to be working. Similarly, selection is negative when $\mathrm{E}(Y \mid E=1, X, G) \leq \mathrm{E}(\mathcal{Y} \mid E=0, X, G)$. The non-participation effect only magnifies the role of $\mathrm{E}(\mathcal{Y} \mid E=0, X, G)$ : for higher non-participation rates, the more missing information there is on wages of individuals out of employment.

Either positive and negative rules can be justified by labor supply models. But without prior information on the selection effect, $\mathrm{E}(\mathcal{Y} \mid E=0, X, G)$ could assume a wide range of values. A seemingly conservative approach is to put bounds on $\mathrm{E}(\mathcal{Y} \mid X, G)$. With $\mathcal{Y}$ bounded, the best and worse case scenarios can be constructed by taking $\mathrm{E}(\mathcal{Y} \mid E=0, X, G)$ to be either 
its extreme lowest or highest values $\underline{\mathcal{Y}}$ and $\overline{\mathcal{Y}}$ :

$$
\begin{aligned}
\mathrm{E}(Y \mid E=1, X, G) \operatorname{Pr}(E=1 \mid X, G)+ & \underline{\mathcal{Y}} \operatorname{Pr}(E=0 \mid X, G) \\
\leq & \mathrm{E}(\mathcal{Y} \mid X, G) \leq \\
\mathrm{E}(Y \mid E & =1, X, G) \operatorname{Pr}(E=1 \mid X, G)+\overline{\mathcal{Y}} \operatorname{Pr}(E=0 \mid X, G) .
\end{aligned}
$$

Applying bounds to the evolution of the gender wage gap is further challenged by differences in selection and participation across genders and across time. This can be seen by letting $X$ refer to time $T$, with $T \in\left\{t_{1}, t_{2}\right\}$ :

$$
\begin{aligned}
\Delta\left(t_{2}\right)-\Delta\left(t_{1}\right)=\left\{\mathrm{E}\left(\mathcal{Y} \mid T=t_{2}, G=1\right)\right. & \left.-\mathrm{E}\left(\mathcal{Y} \mid T=t_{2}, G=0\right)\right\} \\
& -\left\{\mathrm{E}\left(\mathcal{Y} \mid T=t_{1}, G=1\right)-\mathrm{E}\left(\mathcal{Y} \mid T=t_{1}, G=0\right)\right\},
\end{aligned}
$$

where each term in the expression has bounds given by (2). Even if wide (e.g., including zero), the resulting bounds from (3) highlight the magnitude of the missing data problem. The lack of information on $\mathrm{E}(\mathcal{Y} \mid E=0, X, G)$ becomes more important the higher the nonparticipation rate, and this is particularly troublesome in studies of the gender wage gap, as female participation rate is still relatively low, despite increasing over the past decades. Existing attempts to sign $\Delta\left(t_{2}\right)-\Delta\left(t_{1}\right)$ must impose more structure into a selection model.

\subsection{Existing Approaches}

There are three main approaches in the literature on selection with missing outcomes. The first approach uses information on the observed covariates $X$ and restrictions motivated by economic models to impute values for the missing data [Neal and Johnson, 1996, Johnson et al., 2000, Neal, 2004, Blau and Kahn, 2006, Olivetti and Petrongolo, 2008]. For example, if non-participants earn less than median wages, imputing zero wages for those with missing information does not bias the estimate of median wages [Johnson et al., 2000]. Alternatively, if selection into employment is purely random after we control for a very detailed set of 
observed covariates, one can match similar individuals based on $X$, and impute the wages of non-participants by the mean wage of participants [Olivetti and Petrongolo, 2008].

A second approach acknowledges that selection can be based on unobservables and models the self-selection process. In general, the correction procedure amounts to including an extra term in the wage equation, the control function, which is either known, as in parametric models [Heckman, 1974, Mulligan and Rubinstein, 2008], or, when unknown, estimated by semi-parametric methods (see Vella [1998] for a detailed discussion on this literature). Identification under the control function approach requires an exclusion restriction ${ }^{1}$, that is, an instrument $Z$ that shifts employment but is unrelated to wages, and the estimated model generally falls into a variant of a single index partially linear model.

The third approach, while still accounting for unobserved selection, does not explicitly model self-selection. This bounding approach to the selection problem has equations similar to (2) as its starting point, and narrows bounds using restrictions motivated by econometric or economic theory. For example, Manski [1990] shows how the availability of an instrument can reduce the width of the bounds. Intuitively, an instrument shifts participation and reduces the weight placed on the unobserved wages of non-participants. In Blundell et al. [2007], the availability of an instrument is combined with a positive selection assumption and an additivity restriction in the wage equation for an empirical assessment of the gender wage gap in the UK.

A common denominator in all three branches of the literature is the imposition of some structure into the selection process. In imputation methods, selection on unobservables is assumed away as missing wage information is filled in based on observed covariates. Parametric, semi-parametric methods and the bounding approach all account for unobserved selection, but either assume a unique rule (or correction procedure), which is invariant to unobservable characteristics, or assume knowledge of the sign of average selection in order to derive informative answers from the bounds.

\footnotetext{
${ }^{1}$ The exclusion restriction is not necessary in parametric models, but, in practice, identification without an instrument is weak, as the correction term is often a linear function of the variables entering the outcome equation directly [Vella, 1998].
} 
Where female employment and wages are concerned, such assumptions may be especially tenuous. While positive selection is the norm for male selection, negative selection is also plausible for women. Neal [2004] provides evidence of different female selection rules by race. More generally, selection rules can also differ by unobserved characteristics. Where both positive and negative rules co-exist, the sign of average selection is also debatable.

The approach pursued in this paper departs from the previous literature in that it does not impose any structure on (or recover information about) the selection rule. It instead targets identification of mean wages under unobserved heterogeneity in the selection rule. By unobserved, I mean that the positive and negative selection rules can also depend on the unobservable determinants of wages and employment. The next section provides a stylized example illustrating those core features.

\subsection{Unobserved Heterogeneity in Selection: An Example}

Let female employment and wages be generated by the model:

$$
\begin{gathered}
E_{i}=\mathbf{1}\left[\alpha+\gamma Z_{i} \geq \epsilon_{i}\right] \\
Y_{i}=\mathcal{Y}_{i} \text { if } E_{i}=1 \\
Z_{i} \Perp\left(\mathcal{Y}_{i}, \epsilon_{i}\right),
\end{gathered}
$$

with wages specified by the rule:

$$
\mathcal{Y}_{i}= \begin{cases}\left(\rho_{\mathrm{N}} * \sigma_{\mathrm{N}} / \sigma_{\epsilon}\right) * \epsilon_{i}+\zeta_{i} & \text { if } \epsilon_{i} \geq 0(\text { type } \mathrm{N}) \\ \left(\rho_{\mathrm{P}} * \sigma_{\mathrm{P}} / \sigma_{\epsilon}\right) * \epsilon_{i}+\zeta_{i} & \text { if } \epsilon_{i}<0(\text { type } \mathrm{P})\end{cases}
$$

and parametrization and data generating process (DGP) given by: 


$$
\begin{gathered}
\epsilon_{i} \sim N\left(0, \sigma_{\epsilon}^{2}\right), \quad \sigma_{\epsilon}=4 \\
Z_{i} \sim \operatorname{Binomial}(0.5) \\
\alpha=2.5, \quad \gamma=-5 \\
\zeta_{i} \sim N(0,1) \\
\left(\rho_{\mathrm{N}}, \sigma_{\mathrm{N}}\right)=(0.5,4) \\
\left(\rho_{\mathrm{P}}, \sigma_{\mathrm{P}}\right)=(-0.5,4) .
\end{gathered}
$$

The model in (4) is a standard labor supply model where $\mathcal{Y}_{i}$ and $\epsilon_{i}$ are the unobservables that jointly determine employment and wages, which are generally correlated. In the terminology of those models, $\epsilon_{i}$ corresponds to the difference in the unobservables of the reservation and market wage equations ${ }^{2}$. Under a joint normality assumption, the correlation between $\mathcal{Y}_{i}$ and $\epsilon_{i}$ determines the sign of selection: if the correlation is positive, selection is said to be negative, and vice-versa ${ }^{3}$.

Heterogeneity in the selection rule is captured by the co-existence of two rules, $\mathrm{N}$ and $\mathrm{P}$, corresponding to a negative and a positive selection mechanism, respectively, as seen in (5). This heterogeneity is unobserved because it depends on $\epsilon_{i}$, being of type $\mathrm{N}$ if $\epsilon_{i} \geq 0$ and of type $\mathrm{P}$ if $\epsilon_{i}<0$. Since $\epsilon_{i} \sim N\left(0, \sigma_{\epsilon}^{2}\right)$, the two types are equally likely. If $\rho_{\mathbb{N}}=\rho_{\mathrm{P}}$, we return to the conventional setup.

Table 1 displays summary statistics for 1,000 datasets, with 10,000 observations each, generated by the above model and DGP. Panel A reports some statistics on wages and employment that would be observed by researchers. Mean wages among the employed are 1.596, and are based on information about the $50 \%$ of the population that chooses to participate. The instrument $Z$ decreases employment by 0.469 percentange points $(0.734-0.265)$.

Panel $\mathrm{B}$ displays information on $\mathcal{Y}$ by the underlying selection rule, which could only be

\footnotetext{
${ }^{2}$ This can be seen by letting the reservation wages $Y_{i}^{R}$ be given by $Y_{i}^{R}=-\alpha-\gamma Z_{i}+\xi_{i}$. Thus, $E_{i}=1$ if $\mathcal{Y}_{i} \geq Y_{i}^{R}$ or, alternatively, $\alpha+\gamma Z_{i} \geq \xi_{i}-\mathcal{Y}_{i}=\epsilon_{i}$.

${ }^{3}$ When comparing $\mathcal{Y}_{i}$ and $-\epsilon_{i}$ - the difference between market and reservation wages - the sign of the correlation and selection go on the same direction.
} 
recovered under knowledge of the true model. In this example, the positive and negative rules roughly cancel each other out, and the average of potential wages is very close to the observed mean wages among the employed. Because the two selection rules are symmetric, type $\mathrm{N}$ and $\mathrm{P}$ women have the same distribution of wages. This can be seen in Figure 1, which plots the distribution of wages for one of the 1,000 datasets. The two types only differ with respect to $\epsilon_{i}$, and, consequently, on the likelihood of employment. Individuals with selection rule $\mathrm{N}$, are less likely to be employed than type $\mathrm{P}$, as higher values of $\epsilon_{i}$ meet the the employment threshold equation less frequently. As would be expected, type $\mathrm{N}$ individuals are negatively selected into employment, with $\mathrm{E}(\mathcal{Y} \mid E=0, \mathrm{~N}) \geq \mathrm{E}(\mathcal{Y} \mid E=1, \mathrm{~N})$, as $\rho_{\mathrm{N}}>0$. Type $\mathrm{P}$ individuals are positively selected.

This model captures the idea that the selection rule will differ according to how well a women will fare in terms of reservation wages (relative to market wages), which is what $\epsilon_{i}$ represents. Women with $\epsilon_{i} \geq 0$ have their employment decision strongly guided by high reservation wages, and among them, the ones that work have the lowest market wages (negative selection). The symmetric reasoning holds for women with $\epsilon_{i}<0$. A microfounded model yielding these features has been proposed by Neal [2004], where selection heterogeneity arises from differences in marriage market prospects.

Panel $\mathrm{C}$ presents estimates on $\mathcal{Y}$ under two common approaches used to recover female wages (and the gender gap): a parametric selection model that assumes joint normality of unobservables and a unique selection rule, as in Mulligan and Rubinstein [2008], and nonparametric bounds on mean and median wages, assuming the sign of the average selection is known, as in Blundell et al. [2007].

The parametric selection model includes the Mills ratio as a control in the wage equation, and estimates the mean wages to be 0.605 , which deflates its true measure of 1.595 by more than half. Based on that estimation framework, one would conclude that selection is positive, as wages of the employed, 1.596, are higher than the estimated measure of $\mathrm{E}(\mathcal{Y})$, even though positive selection is no more likely than negative selection.

Placing non-parametric bounds on mean and median wages combines the availability of the instrument $Z$ with the assumption of either a positive or negative average selection 
mechanism. Information on the construction of the bounds is contained in Appendix II. Since the employment rate in the example is low, best and worse case bounds on $\mathrm{E}(\mathcal{Y})$ are very wide, and range from a low of 0.119 to a high of 3.229. Imposing average positive selection reduces the upper bound to 1.280, and the resulting bounds range from 0.119 to 1.280. Similarly, under negative selection the lower bound becomes 2.468, with the upper bound of 3.229 being maintained. Bounds under either positive or negative selection assumptions also miss $\mathrm{E}(\mathcal{Y})$, as average selection in this example is zero. With respect to median median wages, bounds are relatively tighter, but still range from 0.501 to 1.825 . As in the case of mean wages, the positive selection assumption reduces upper bound to 1.129, and misses median wages, which is 1.465 in this example. The negative selection assumption is rejected in this case, as upper and lower limits cross.

This example shows that both the parametric correction and the non-parametric bounds that sign the average selection may fail to recover mean (or median) potential wages under unobserved heterogeneity in the selection rule. However, the example given by equations (4) to (6) is one among other possible models of female employment selection. Below I examine the robustness of these results to some alternative modeling strategies, but in the next section I consider a broader class of models, with arbitrary heterogeneity in selection. I show that a meaningful measure of potential wages can still be recovered in those models if some instrumental variable conditions are met.

Different Proportion of Types How do the parametric correction and non-parametric bounds fare as the degree of selection heterogeneity diminishes? In the example, type $\mathrm{N}$ and $\mathrm{P}$ are equally likely, but different proportion of types can be generated by considering different $\epsilon_{i}$ thresholds in equation (5). The parametric correction fails even for small heterogeneity (eg, $10 \%$ or $90 \%$ type $\mathrm{P}$ ), and always conclude positive selection. As for bounds on median wages, the tolerance is slighlty higher, but for any proportion of P type individuals between $20 \%$ and $80 \%$, negative selection would be rejected and bounds under positive selection would miss median wages.

Symmetric Assignment of Types Opposite results are obtained when modifying equa- 
tion (5) to let $\epsilon_{i} \geq 0$ denote the individual under a type $\mathrm{P}$ rule and $\epsilon_{i}<0$ the ones under a type $\mathrm{N}$ rule. The parametric correction concludes negative selection, whereas bounds on median wages reject the positive selection assumption and do not recover median wages under the negative selection assumption.

Equal Participation Rates Are the bias in estimates due to differences in employment participation across the types? For example, is positive selection concluded because work participation is higher among the P type? Is the negative selection assumption rejected for the same reason under the bounding approach? The answer is yes for a selection model in line with equations (4) to (6). Equal proportion of types and equal participation rates across them can be generated by letting $\left(\alpha_{\mathrm{N}}, \gamma_{\mathrm{N}}\right)=(4,-2)$ and $\left(\alpha_{\mathrm{P}}, \gamma_{\mathrm{P}}\right)=(-1,-3)$ in the employment threshold equation, for instance. The parametric correction gets close to mean wages, and neither positive nor negative selection can be rejected under the bounding approach.

\section{A Local Measure of Potential Wages}

\subsection{Identification}

This section is built upon the potential outcome notation of causal models, as in Rubin [1974] and Heckman [1990]. In fact, the selection problem with missing outcomes is a particular case of treatment effect models, with the outcome being observed only for the individuals that opt in. In contrast to those models, however, the goal is to recover information for the entire population, rather then inferring the causal effect of a treatment.

I adhere to two conventions in the literature. First, I do not explicitly model observed covariates, and all is taken to be conditional on $X=x$. Second, I abstract from general equilibrium effects, even thought they might be a relevant concern when extrapolating the results to universal participation.

For a binary $Z$, define $E_{1}$ and $E_{0}$ as the potential participation status when $Z$ is externally set to 1 and 0 respectively. Following Angrist et al. [1996], define $\left(E_{1}=1, E_{0}=1\right)$ as the 
"always employed," $\left(E_{1}=1, E_{0}=0\right)$ the "employment compliers," $\left(E_{1}=0, E_{0}=1\right)$ the "employment defiers," and $\left(E_{1}=0, E_{0}=0\right)$ the "never employed." The model reads:

(AI) Existence of an Instrument:

Independence: $\quad Z \Perp\left(\mathcal{Y}, E_{0}, E_{1}\right)$.

$$
\begin{aligned}
& \text { Nontrivial } Z: \quad \Psi=\operatorname{Pr}(E=1 \mid Z=1)-\operatorname{Pr}(E=1 \mid Z=0) \neq 0, \\
& \text { with }\left\{\begin{array}{l}
\operatorname{Pr}(E=1 \mid Z=1)>0 \\
\operatorname{Pr}(E=1 \mid Z=0)>0
\end{array} \text { when } \Psi<0\right.
\end{aligned}
$$

(AII) Exclusion Restriction:

$$
\begin{gathered}
Y=\mathcal{Y} \text { if } E=1, \\
E=Z E_{1}+(1-Z) E_{0} .
\end{gathered}
$$

(AIII) Monotonicity: Either $E_{1} \leq E_{0}$ or $E_{1} \geq E_{0}$ for all individuals.

Under (AI)-(AII), mean wages for the "always employed," $\mathrm{E}\left(\mathcal{Y} \mid E_{1}=1, E_{0}=1\right)$, can be identified. For $E_{1} \leq E_{0}$ :

$$
\begin{aligned}
\mathrm{E}(Y \mid E=1, Z=1) & =\mathrm{E}\left(\mathcal{Y} \mid E_{1}=1, Z=1\right) \\
& =\mathrm{E}\left(\mathcal{Y} \mid E_{1}=1\right) \\
& =\mathrm{E}\left(\mathcal{Y} \mid E_{0}=1, E_{1}=1\right)
\end{aligned}
$$

For $E_{1} \geq E_{0}$, a similar reasoning shows that $\mathrm{E}\left(\mathcal{Y} \mid E_{1}=1, E_{0}=1\right)$ is identified by $\mathrm{E}(Y \mid E=$ $1, Z=0)^{4}$. In contrast to the treatment effect literature, which uses the IV to identify the treatment effect among "compliers", the IV is used here to identify potential wages for the subsample of individuals who do not change their employment decision and remain working no matter the value of $Z$.

\footnotetext{
${ }^{4}$ Note that $Z \Perp\left(\mathcal{Y}, E_{0}, E_{1}\right)$ implies $\mathrm{E}\left(\mathcal{Y} \mid E_{1}=1, Z=1\right)=\mathrm{E}\left(\mathcal{Y} \mid E_{1}=1\right)$ and $\mathrm{E}\left(\mathcal{Y} \mid E_{0}=1, Z=0\right)=$ $\mathrm{E}\left(\mathcal{Y} \mid E_{0}=1\right)$, which are weaker identification conditions. I maintain $Z \Perp\left(\mathcal{Y}, E_{0}, E_{1}\right)$ for ease of exposition.
} 
Assumption (AIII) is a monotonicity restriction that rules out the existence of either $\left(E_{0}=0, E_{1}=1\right)$ or $\left(E_{0}=1, E_{1}=0\right)$ behavior $^{5}$. Since the estimator of $\mathrm{E}\left(\mathcal{Y} \mid E_{0}=1, E_{1}=1\right)$ is sensitive to the excluded type, the direction of monotonicity needs to be inferred in a first step.

A simple check comes by noting that the model represented by (AI)-(AIII) is alternatively represented by the model in (4), which was previously used in the simulation exercise ${ }^{6}$. Under (AIII), the direction of monotonicity can be recovered by verifying whether the instrument decreases or increases the employment probability, ie, whether $\Psi=\operatorname{Pr}(E=1 \mid Z=1)-$ $\operatorname{Pr}(E=1 \mid Z=0)$ is negative or positive. A negative $\Psi$ rules out the $\left(E_{0}=0, E_{1}=1\right)$ behavior, and monotonicity holds in the decreasing direction, with $E_{1} \leq E_{0}$. Similarly, a positive $\Psi$ rules out the $\left(E_{0}=1, E_{1}=0\right)$ behavior, and monotonicity holds in the increasing direction, with $E_{1} \geq E_{0}{ }^{7}$.

Moving back to Table 1 , panels $\mathrm{A}$ and $\mathrm{D}$ show that $\mathrm{E}(Y \mid E=1, Z=1)$ matches $\mathrm{E}\left(\mathcal{Y} \mid E_{1}=\right.$ $\left.1, E_{0}=1\right)$. This is the case because $\Psi<0$, which implies monotonicity in a decreasing direction, with $E_{1} \leq E_{0}$. Mean wages for the "always employed" can also be recovered under the alternative modeling strategies of Section 2.3, as the instrumental variable conditions are also met for them.

\footnotetext{
${ }^{5}$ Monotonicity in selection has also been considered in treatment effect models where the outcome of interested is missing for some individuals in both treated and non-treated groups [Angrist, 1995, Zhang et al., 2008, Lee, 2009].

${ }^{6}$ The equivalence of both formulation has been established by Vytlacil [2002].

${ }^{7}$ This can be seen by examining the expressions for $\operatorname{Pr}\left(E_{0}=0, E_{1}=1\right)$ and $\operatorname{Pr}\left(E_{0}=1, E_{1}=0\right)$. For $\gamma<0$ :

$$
\begin{aligned}
\operatorname{Pr}\left(E_{0}=1, E_{1}=0\right) & =\operatorname{Pr}\left(\alpha \geq \epsilon_{i}, \alpha+\gamma<\epsilon_{i}\right) \\
& =\operatorname{Pr}\left(\alpha+\gamma<\epsilon_{i} \leq \alpha\right) \\
& =F_{\epsilon}(\alpha)-F_{\epsilon}(\alpha+\gamma) \\
& =\operatorname{Pr}(E=1 \mid Z=0)-\operatorname{Pr}(E=1 \mid Z=1) \\
\operatorname{Pr}\left(E_{0}=0, E_{1}=1\right) & =\operatorname{Pr}\left(\alpha<\epsilon_{i}, \alpha+\gamma \geq \epsilon_{i}\right)=0 .
\end{aligned}
$$
}

Similarly, for $\gamma>0$ :

$$
\begin{aligned}
& \operatorname{Pr}\left(E_{0}=1, E_{1}=0\right)=0 \\
& \operatorname{Pr}\left(E_{0}=0, E_{1}=1\right)=\operatorname{Pr}(E=1 \mid Z=1)-\operatorname{Pr}(E=1 \mid Z=0) .
\end{aligned}
$$

Thus, since $\Psi=\operatorname{Pr}(E=1 \mid Z=1)-\operatorname{Pr}(E=1 \mid Z=0)$ is either positive or negative, either $\left(E_{0}=1, E_{1}=0\right)$ or $\left(E_{0}=0, E_{1}=1\right)$ will be assumed away by monotonicity. 
Finally, I note that conditions (AI)-(AIII) also allow identification of mean wages of the "employment defiers" when $\Psi<0$ and mean wages of the "employment compliers" when $\Psi>0^{8}$. In the empirical application that follows, I focus on the estimation of mean wages of the "always employed" women, as female employment attachment is low relative to men. This approach yields a comparable group of men and women, which bridges differences in attachment across gender in the measurement of the wage gap.

\subsection{Estimation}

The parameter of interest is the gender wage gap between the men and women of similar characteristics. Therefore, gender gaps are computed within cells of $X$, the vector of covariates. Abstracting from selection effects in the male population, and using $Z$ as an instrument for female employment, a first step inspects whether

$$
\Psi_{x t(G=1)}=\operatorname{Pr}(E=1 \mid Z=1, X=x, T=t, G=1)-\operatorname{Pr}(E=1 \mid Z=0, X=x, T=t, G=1)
$$

is positive or negative. Under the monotonicity assumption (AIII), a negative $\Psi_{x t(G=1)}$ implies $E_{1} \leq E_{0}$, rendering $E(Y \mid E=1, Z=1, X=x, T=t, G=1)$ as the local estimator of women's wages. When $\Psi_{x t(G=1)}$ is positive, the estimator is $E(Y \mid E=1, Z=0, X=$ $x, T=t, G=1)$.

The second step is a simple OLS regression where the instrument $Z$ enters interacted with gender:

$$
Y_{i}=\beta_{0 x t}+\beta_{1 x t} G_{i}+\beta_{2 x t} G_{i} * Z_{i}+u_{i} .
$$

${ }^{8}$ The estimators are given by

$$
\begin{aligned}
& \mathrm{E}\left(\mathcal{Y} \mid E_{0}=1, E_{1}=0\right)=\frac{p(0)}{p(0)-p(1)} \mathrm{E}(Y \mid E=1, Z=0)-\frac{p(1)}{p(0)-p(1)} \mathrm{E}(Y \mid E=1, Z=1) \\
& \mathrm{E}\left(\mathcal{Y} \mid E_{0}=0, E_{1}=1\right)=\frac{p(1)}{p(1)-p(0)} \mathrm{E}(Y \mid E=1, Z=1)-\frac{p(0)}{p(1)-p(0)} \mathrm{E}(Y \mid E=1, Z=0)
\end{aligned}
$$

where $p(z)=\operatorname{Pr}(E=1 \mid Z=z)$. 
The local measure of the gap is then given by:

$$
\begin{aligned}
& \Delta(x, t)=\mathrm{E}\left(\mathcal{Y} \mid E_{1}=1, E_{0}=1, X=x, T=t, G=1,\right)-\mathrm{E}(\mathcal{Y} \mid X=x, T=t, G=0) \\
& =\mathrm{E}(Y \mid E=1, Z=1, X=x, T=t, G=1)-\mathrm{E}(Y \mid E=1, X=x, T=t, G=0) \\
& =\left\{\begin{array}{cc}
\beta_{1 x t} & \text { if } \Psi_{x t(G=1)}>0 \\
\beta_{1 x t}+\beta_{2 x t} & \text { if } \Psi_{x t(G=1)}<0 .
\end{array}\right.
\end{aligned}
$$

If male selection effects are of concern, and $Z$ is a valid instrument for the male population as well, a first step, as in equation (8), should also be estimated for $G=0$. The second step is a variant of equation (9), where the instrument interact with both gender indicators:

$$
Y_{i}=\beta_{0 x t}+\beta_{1 x t} G_{i}+\beta_{2 x t} G_{i} * Z_{i}+\beta_{3 x t}\left(1-G_{i}\right) * Z_{i}+u_{i} .
$$

The local measure of the gap between "always employed" men and women is given by:

$$
\begin{aligned}
\Omega(x, t)=\mathrm{E}\left(\mathcal{Y} \mid E_{1}=1, E_{0}=1,\right. & X=x, T=t, G=1) \\
-\mathrm{E}\left(\mathcal{Y} \mid E_{1}=1, E_{0}=1, X=x, T=t, G=0\right) & \\
= & \begin{array}{cc}
\beta_{1 x t} & \text { if } \Psi_{x t(G=1)}>0 \text { and } \Psi_{x t(G=0)}>0 \\
\beta_{1 x t}-\beta_{3 x t} & \text { if } \Psi_{x t(G=1)}>0 \text { and } \Psi_{x t(G=0)}<0 \\
\beta_{1 x t}+\beta_{2 x t} & \text { if } \Psi_{x t(G=1)}<0 \text { and } \Psi_{x t(G=0)}>0 \\
\beta_{1 x t}+\beta_{2 x t}-\beta_{3 x t} & \text { if } \Psi_{x t(G=1)}<0 \text { and } \Psi_{x t(G=0)}<0 .
\end{array}
\end{aligned}
$$

\section{The Gender Wage Gap in the US}

\subsection{Data}

The data used in this paper comes from the Annual Demographic File (ADF) of the CPS from 1976 to 2005 and follows the sample restriction typically employed in studies of the gender gap: I focus on white non-Hispanic adults between ages of 25 and 44. The age restriction 
is tighter than in previous studies ${ }^{9}$ because the instrument employed in this paper, which is fertility related, affects women of childbearing age. I define participation by two employment variables: any work and full-time-full-year work (35+ hours per week and 50 weeks or more) during the year. The outcome variable is log hourly wages. More details on the sample is found in Appendix I.

The instrument $Z$ is a binary indicator for a presence of a child less than six years-old in the family. The bulk of the variation in this variable comes before age 44 , as only $2 \%$ of women between 45-54 have a child younger than six years old. Moreover, although this variable is originally multivalued in the CPS survey, roughly $90 \%$ of my sample has either no children or only one child below the age of six, motivating the classification of the binary instrument. The choice of the instrument, although questionable, follows the previous literature. In Heckman [1974], one of the seminal works on female selection, number of children is used as an explanatory variable in the shadow price function. More recently, Mulligan and Rubinstein [2008] have used number of children younger than six interacted with marital status as variables determining employment, which are excluded from the market wage equation. A discussion about this instrument, and its relation to assumptions (AI)-(AIII), is found in Section 6 of this paper.

Summary statistics for the data are displayed in Table 2. Female participation increases from $65 \%$ to $80 \%$ over the period of analysis, a trend that is followed by the full-time full-year (FT) rate, at lower levels. Still by 2005, FT wages are only observed for $50 \%$ of women in the sample. The very high degree of missing wage information in the FT sample justifies having any employment as an alternative participation variable, bearing in mind that hourly wages for part-time workers could be smaller on average, and that the fraction of part-timers should be higher in the female population. Relative to women, male employment rates are substantially more stable, though over this period FT wages are not observed for more than $20 \%$ of men.

The race, ethnicity and age restrictions on the sample makes the universe of men and

\footnotetext{
${ }^{9}$ In Mulligan and Rubinstein [2008], the sample encompasses ages 25-54, and in Blau and Kahn [2006] it includes ages 18-65
} 
women very similar in observables aside from two other characteristics, which are marital status and education. Although the fraction married is similar for both male and female populations, the education distribution and its evolution between 1976 and 2005 does not display a similar pattern across gender. For instance, the fraction with a college degree or more increases 5 percentage points for men, a 16\% change, whereas it increases by 16 points for women, an almost twofold change. The empirical analysis that follows takes $X$ to be education and stratifies results by 4 groups: less than high school, high school graduates, some college and college graduate or more.

\subsection{Results}

Since the selection problem is more severe for women - made evident by their low employment rates when compared to men - this section abstracts from male selection and takes equations (8) and (9) as benchmarks in the estimation.

Table 4 displays the first stage results stratified by the four education groups for the first and last years of the sample. The presence of a child under six decreases female employment, both for any work or full time work, with the effect being stronger at higher levels of education (where participation levels are higher). Overall, results indicate that the presence of a child younger than six decreases participation, and the sensitivity is slightly smaller for years 2001-05 relative to $1976-80$.

Since $\hat{\Psi}_{x t(G=1)}$ is negative for all education groups and periods, implying monotonicity in

a decreasing direction, the local measure of the gender wage gap is recovered by $\hat{\beta}_{1 x t}+\hat{\beta}_{2 x t}$ estimated through equation (9). Results are displayed in Table 5. Each panel of the table, one for each education group, has four regressions, which differ according to years, 1976-1980 versus 2001-2005, and to the participation classification, any employment or FT.

Education-wise comparison of the gender gaps indicate that they get smaller (in absolute value) as education increases, and women in the high end of the education distribution are found less subject to a penalty. Nonetheless, the local measure of the wage gap has decreased for all education groups between 1976 and 2005. The largest improvement in the 
gap, a twofold reduction, has occurred for the group with a college degree or more. For them, note that the local gap has closed by .20 log points, whereas the observed (or uncorrected) gap, displayed in the last line of the panel, indicates only a .10 log point reduction.

The above results can be summarized by weighting each education gap $\Delta(x, t)$ by corresponding education proportions. Since the education distribution varies over time and by gender (see Table 2), alternative weighting schemes can be employed. I consider four types of weights and display results in Table 6 . The first weight, the female variable weight, uses the female education proportions in each time period, $p_{x t}=\operatorname{Pr}(X=x \mid G=1, T=t)$, and computes the average gap by:

$$
\Delta(t)=\sum_{x=1}^{4} \Delta(x, t) * p_{x t} .
$$

The observed evolution of the gap, without selection corrections, provides a modest proxy for the gap of "always employed women": .306 versus .238 points for the ones with any employment and .258 versus .182 for the ones in full time full year work. As changes in this average gap reflect changes in each conditional gap as well as changes in the education composition of the female population, the next two weights in Table 6 hold education fixed using either its $1976-80$ or its 2001-2005 proportions. The female fixed 1976-1980 weight uses $p_{x t=1976-1980}$ and the female fixed 2001-2005 weight uses $p_{x t=2001-2005}$. These alternative weighting schemes show that although part of the improvement is due to changes in the educational composition of the female workforce, the bulk of the change is due to a uniform reduction in the gender gap for each education category. Taking the education proportions in the male population as weights, $p_{x t}^{M}=\operatorname{Pr}(X=x \mid G=0, T=t)$, the gains are slightly smaller and reflect the fact that the education proportions in the female population are skewed towards the groups with the highest gains. 


\subsection{Comparison to Previous Gender Gap Estimates}

Putting the results of the previous section into perspective, Figure 2 compares $\Delta(t)$ to other measures estimated in literature: the observed (or "uncorrected") evolution of the gap and the gap from a parametric selection model. Appendix II outlines how those two measures where obtained in my sample.

The wage gaps portrayed in the figure has participation defined as full time work and weighs the education groups by $p_{x t}$. The initial and final estimates of the local gap in the figure correspond to the numbers in the first line of Table 6, panel B, columns (1)-(3): an improvement of $.25 \mathrm{log}$ wage points, from -0.521 to -0.263 . The observed gap displays a similar trend, with the measured improvement being lower, at .18 points, from -0.447 to 0.265. In contrast, the measure from a parametric selection model shows no improvement of the pay gap, which remains around -.30 points from 1976 to 2005. Note that these numbers closely track the estimates in the literature ${ }^{10}$.

I also estimate non-parametric bounds on the median wage gap in my sample following the procedure and assumptions in Blundell et al. [2007], who have used data from the UK. Details about the computation of the bounds are contained in Appendix II. Two key features are worth noting. First, bounds pertain the median, rather than the mean, wage gap, as bounds on the mean wage gap require wages to have a bounded support, which is likely not the case. Second, for purpose of comparison to Blundell et al. [2007], I maintain the results stratified by education groups and assume that the changes in the education gap is the same for all ages. I replicate their findings for the US, and find that a positive selection assumption $^{11}$ is key to determining that the relative wages of women have increased. This result can be seen in Figure A.I, which plots bounds on the changes of the gender wage gap between 1976 and 2005. A positive number indicates that gap in 2005 is lower relative to

\footnotetext{
${ }^{10}$ Blau and Kahn [2006] measure the observed differential as being -.459 in 1979 and -.227 in 1998 using PSID data. Mulligan and Rubinstein [2008] measure the observed differential to be -.414 in 1975-79 and -.254 in 1995-1999 using the CPS ADF data. Their parametric selection estimator of the gap is -..337 in 1975-79 and -.339 in 1995-1999.

${ }^{11}$ Positive selection is imposed through a stochastic dominance assumption as defined in Blundell et al. [2007].
} 
1976, and a negative number indicates it is higher.

What do all these estimates reflect? On the one hand, selection considerations are very important for measuring wages, as female employment rates are still relatively low. This would, in principle, make the observed evolution of the gap a poor proxy for its "true" evolution. On the other hand, any attempt to correct for selection needs to impose some structure into a selection model. As would be expected, estimates using different strategies and assumptions yield conflicting answers: Mulligan and Rubinstein [2008] find that the gender wage gap has remained stable, whereas Blundell et al. [2007] find an improvement. Moreover, I am able to replicate both these findings in a single US data set illustrating that it is the method that drives the differing results, rather than any difference in sampling, time period, or choice of instrument.

The local measure of the gender gap also needs to impose some structure into the selection problem, with assumptions given by (AI)-(AIII). Taken at face value, these assumptions are no different than the ones already assumed in the parametric selection model, for instance. But the proposed method departs from the literature by not modeling the self-selection process. This consideration is particularly important in the presence of unobserved heterogeneity, as should be the case for women and the labor market.

The trade-off, obviously, is that the estimator applies to a narrow, yet well-defined, subpopulation: women who do not change participation (and remain employed) in the presence of a young child. Nonetheless, this is plausibly the group most comparable to men, as the latter have higher attachment to the labor force and seldom leave their jobs when they have children. In this "apples to apples" comparison, substantial progress in closing the gender wage gap is indeed found.

\section{Robustness}

This section examines the sensitivity of the estimates of the local measure of the gap to: covariates other than education; male selection; and alternative instruments related to the age of the young child present. For the purpose of comparison to the estimates in Figure 2, 
I consider participation to be full time employment, and use the female variable weights $p_{x t}$ when averaging is necessary.

\subsection{Controlling for Other Covariates}

The analysis in previous sections has used education as the single covariate in $X$. However, selection effects may vary along other characteristics, such as age and marital status. In this section, I follow Card [1996] and Lee [2009] and incorporate all available covariates in a "skill" index. The index is used to sort workers into groups of similar characteristics and the local measure of the gender wage gap is computed within the groups.

The procedure is as following. For each period and gender, I estimate a wage equation ${ }^{12}$ and use the model to predict wages for the entire sample, whether working or not. I then compute the four quartiles of the predicted wage distribution and sort observations into each quartile. Finally, for each period, I compute the gender gap between men and women that have the same rank on its own predicted wage distribution. I estimate equations (8) and (9) taking $X$ to be the gender specific predicted wage quartiles. Although the predicted wage distribution varies by gender, this exercise aims to recover gaps under the assumption that the skills are approximately the same, but are rewarded differently in the market place.

Table 7 presents the summary statistics of the the sample by the four quartiles of predicted wages, stratified by period and gender. It confirms that education is an important variable in the classification of skill types. For example, in the 1976-1980 period, the female composition in the lower quartile has education attainment below high school, whereas the upper quartile has women with at least some college education. Nonetheless, it also shows that the other covariates also have explanatory power in the skill classification, and that education is not its unique determinant. A child younger than six years old decreases female full time employment for all skill groups and time periods, as can be seen in the last two lines of panel A.

\footnotetext{
${ }^{12}$ The explanatory variables are: five education dummies (some high school, high school graduates, some college, college graduates and more than college, relative to less than high school education), three age dummies (ages 30 to 34,35 to 39 and 40 to 44, relative to ages 25 to 29) and four marital status dummies (widowed, divorced, separated and never married, relative to married).
} 
Estimates of the local gap are displayed in Figure 3. The local gender wage gap is lower, in level, for the lowest skill group, and possibly reflects minimum wage policy limiting disparities in the low end of the wage distribution. The trend towards wage equality between 1976 and 2005 is verified for all skill groups. But, most strikingly, the figure also shows continuous improvement of the gender wage gap throughout the 1990s for the two upper quartiles of the skill distribution. For purpose of comparison, Figure 4 displays the uncorrected gap by the skill types, and confirms the finding of slowing convergence of the gender gap after 1990, as documented by Blau and Kahn [2006]. Taken together, the two figures show that selection effects have masked substantial improvements in the gap in 1990s.

\subsection{Male Selection}

The approach taken so far has assumed that the observed wage distribution for men proxies the distribution of potential wages. In the US, however, male selection into work may challenge this assumption as one quarter of wage information is missing for the full-time employed sample, as seen in Table 2. If average selection is positive for men, and the ones participating have the highest wages, the results in previous sections constitute an exaggerated estimate of the wage gap, as the average potential wages of men should be lower.

In principle, the presence of a young child can also be used as an instrument for male participation. In fact, the summary statistics in Table 2 show that the full time employment of men increases by $9 \%$ when a young child is present. Relative to women, the sensitivity of male participation to the presence of a young child is smaller and goes in the opposite direction.

Since $\Psi_{x t(G=1)}<0$ and $\Psi_{x t(G=0)}>0$, the gender wage gap between "always employed"

men and women is given by $\hat{\beta}_{1 x t}+\hat{\beta}_{2 x t}$ estimated through equation (10). Results are summarized in Figure 5. Relative to the measure of $\Delta(t)$, which only accounts for female selection, $\Omega(t)$ pictures a reduced wage gap. Male selection considerations becomes more important towards the end of the sample period, as the wedge between $\Delta(t)$ and $\Omega(t)$ gets wider. For 
the 2001-2005 period, the point estimates of $\Delta(t)$ and $\Omega(t)$ are -0.263 and -0.229 , and depart by $.034 \log$ wage points (statistically significant at the $10 \%$ level).

\subsection{Child Age and Female Participation}

The presence of a child younger than six has a substantial impact on women's participation decisions. As seen in Table 2, full time employment of women with a young child is lower by .25 percentage points, almost half of the participation of women with no young child present. Since younger children require more maternal input, participation effects could differ by the age of the child. Most importantly, because the local gap recovers the pay penalty among "always employed" women, the subpopulation that does not change participation when a child younger than, say, one is present should be even more like men in terms of unobservables, such as job commitment. As the age of the youngest child decreases, and having $Z$ as an indicator for his/her presence, the local measure of the gap should be smaller.

I investigate this hypothesis by utilizing an alternative dataset, the June CPS survey. The June CPS has a fertility supplement, available every other year, with information on the birth month and birth year of the last child. I make restrictions similar to the ones in the ADF sample, which are detailed in Appendix I. The new instruments considered, $Z_{j}$, are binary indicators of the presence of a child less than $j$, with $j \in\{1, \ldots, 6\}$, and are considered one at a time.

One shortcome of this alternative dataset is its small sample size, as wage information in the June sample is only recorded for individuals in the outgoing rotation groups (ORG). Therefore, in this section, I will aggregate the June data into more sparse time groups, allocating approximately one quarter of total observation into four periods: 1979 to 1982, 1983 to 1987, 1988 to 1992, and 1994 to 2002. Summary statistics are presented in Table 3. The age of the youngest child alters participation in a similar manner, and the difference in participation between women with and without a child present is relatively constant (around .25 percentage points) for all values of $j$. In fact, full time employment can remain insensitive to the age of the child if women with young children return to part-time jobs. 
Figure 6 summarizes the local gender wage gap using the alternative $Z_{j}$ 's as instruments. The figure suggests that as the age of the young child decreases, the local gender gender wage gap gets smaller. This result is in line with the conjecture that "always employed" women with a very young child share similar unobserved job characteristics with men, and the wage difference among them is tighter. The standard errors of the estimates, however, do not allow the inference that the local gap using $Z_{1}$ is statistically different from the one using $Z_{6}$ for the later periods in the sample.

\section{Discussion}

\subsection{External Validity}

The instrumental variable approach proposed in this paper recovers a local measure of the gender wage gap, the gap in pay between women who would choose to participate whether or not a young child is present and similar men. One criticism of using instrumental variables to recover a local parameter regards the particular and unobserved group of individuals to which the estimates refer to. In the case of the gender gap, however, the subpopulation of always participating women should be the most relevant comparison to men, as, in general, women's attachment to work in the presence of a child is lower than men's. This should make the "always participants" very close to men in important unobserved wage determinants, such as job commitment and motivation.

Nonetheless, in order to inspect the external validity of the estimate to the total population of women, a useful exercise backs out the proportion of "employment defiers," "always employed" and "never employed." Noting that:

$$
\begin{aligned}
& \operatorname{Pr}(E=1 \mid Z=1)=\operatorname{Pr}\left(E_{1}=1\right)=\operatorname{Pr}\left(E_{1}=1, E_{0}=1\right)+\operatorname{Pr}\left(E_{1}=1, E_{0}=0\right) \\
& \operatorname{Pr}(E=1 \mid Z=0)=\operatorname{Pr}\left(E_{0}=1\right)=\operatorname{Pr}\left(E_{1}=1, E_{0}=1\right)+\operatorname{Pr}\left(E_{1}=0, E_{0}=1\right),
\end{aligned}
$$


and using the monotonicity condition $E_{1} \leq E_{0}$, the proportion in each group is given by:

$$
\begin{gathered}
\operatorname{Pr}\left(E_{1}=0, E_{0}=1\right)=\operatorname{Pr}(E=1 \mid Z=0)-\operatorname{Pr}(E=1 \mid Z=1) \\
\operatorname{Pr}\left(E_{1}=1, E_{0}=1\right)=\operatorname{Pr}(E=1 \mid Z=1) \\
\operatorname{Pr}\left(E_{1}=0, E_{0}=0\right)=1-\operatorname{Pr}(E=1 \mid Z=0) .
\end{gathered}
$$

From Table 2 the proportion of "always employed" averages $27.1 \%$ for the entire sample, and becomes quite sizable by 2001-05. For that last period, it reaches $34.7 \%$ of the sample. Insofar as the "always employed" have higher wages than the "never employed" and the "employment defiers," the unconditional average wage gap could be higher than the local measure provided by this paper.

\subsection{The Panel Data Estimator}

The rise in the proportion of "always employed," as discussed in the previous section, raises concern about the comparability of this group in time. In principle, it is possible that improvements in the wage gap reflect better unobserved characteristics of the marginal women who becomes "always employed." In a panel data, however, it is possible to shut down the composition channel down by following the same individuals over time.

The "always employed" can be proxied by the individuals employed in every period of the panel. By definition, the composition of this group is fixed and does not change in time. Thus, changes in the gender wage gap within this group can be solely attributed to improvements in pay parity, such as reduced discrimination. Moreover, the analysis does not rely on the availability of an instrument, as, again by definition, this group is always employed regardless of the instrument considered. This is convenient because assumptions (AI)-(AIII) might fail in non-experimental settings.

Using the panel structure of the March CPS I investigate the changes in the gender wage gap for individuals employed in the two subsequent years of the data. This is possible 
because half of the respondents in year $t$ are again surveyed in $t+1^{13}$. Using the short panel nature of the data ( 2 periods), I estimate yearly changes in the gender wage gap by:

$$
Y_{i}=\delta_{0 t}+\delta_{1 t} G_{i}+\delta_{2 t} \mathbf{1}[t+1]+\delta_{3 t} G_{i} * \mathbf{1}[t+1]+\delta_{4 t} X_{i}+u_{i}
$$

where $\mathrm{t}$ indexes the matched sample between $\mathrm{t}$ and $\mathrm{t}+1$, and $X$ is a vector with three education dummies (high school graduate, some college, college graduate or more, relative to less than high school). The coefficient $\delta_{1 t}$ measures the gender wage gap in $t$, whereas $\delta_{3 t}$ measures the change in the gender wage gap between $t$ and $t+1$ holding fixed the population of men and women who are employed in both periods of time.

Results for $\delta_{3 t}$ are displayed in Table 8, and show that improvements in the gender wage gap cannot be detected within each one year panel, plausibly because the interval is too short to measure gains of continuous employment. However, the compounded sum of $\delta_{3 t}$ bears resemblance to changes in the gender gap for FT workers. Between 1979 to 2004, the change in the gender wage gap in the panel sample $\left(\delta_{1 t=2004^{-}} \delta_{1 t=1979}\right)$ was 0.206 log wage differentials, being close to the cross section measured gains for the "always employed" of 0.258. The compounded sum of $\delta_{3 t}$, while around the same order of magnitude, is not significant at conventional levels mainly due to the negative estimates of $\delta_{3 t}$ in the last years of the panel. Considering the 1979-2002 time frame, the gap changes by 0.197 in the panel sample, and the compounded sum of ranges from 0.174 to 0.223 , being statistically significant at the $10 \%$ level.

Convergence in the gender wage gap is verified in the panel data approach for FT workers, but not for part-timers as defined by any choice of hours. Thus, for the later, improvements in the gender wage gap could be reflecting changes in the pool of part-timers along the years. This exercise points to compositional changes in the extensive margin of women choosing

\footnotetext{
${ }^{13}$ Each individual in the CPS monthly sample is eligible for eight interviews: four consecutive interviews followed by other four eight months after the fourth. Thus, individuals in their first to fourth interview in March of year $\mathrm{t}$ are again interviewed in March of $\mathrm{t}+1$. While the match of surveys prior to 1979 is possible, the omission of identifiers makes this process tenuous, and I abstract from those years in my analysis. Neither March 1984 and March 1985, nor March 1994 and March 1995, can be merged because of revisions in household identifiers [Madrian and Lefgren, 1999]. The match rate for two subsequent periods in my sample ranges from $30 \%$ to $57 \%$.
} 
employment, but not in the intensive margin of women choosing FT work. Holding fixed the composition of FT workers, improvements in the gender wage gap are indeed found.

\subsection{The Identifying Assumptions}

As in treatment effect models, solving the problem of selection with missing outcomes generally requires an instrument that shifts participation and is excluded from the outcome equation. The literature, however, has treated the IV assumption "quite casually," viewing identification as an intrinsic econometric problem, with little emphasis on its economic content [Moffit, 1999].

The discussion is often neglected because it is very hard to defend all the necessary assumptions for a valid instrument, particularly in a non-experimental setting. The use of the presence of a young child as an IV in the female selection problem is no different. Although very little can be done when the instrument fails the independence condition (AI), which is the case if fertility decisions are not exogenous to employment and wages [Angrist and Evans, 1998, Browning, 1992, Willis, 1987], the failure of assumptions (AII) and (AIII) are not necessarily catastrophic. In this section, I follow Angrist et al. [1996] and discuss the sensitivity of the local measure of wages to the exclusion and monotonicity restrictions.

\section{Monotonicity}

The monotonicity condition rules out the existence of type $\left(E_{1}=1, E_{0}=0\right)$ women, and would be violated if there are women who do not work, but start working once a child is present, to complement household income, for instance. By manipulation of the terms in equation (7), the bias of the local wage estimator is given by:

$$
\begin{aligned}
\mathrm{E}(Y \mid E=1, Z=1)- & \mathrm{E}\left(\mathcal{Y} \mid E_{1}=1, E_{0}=1\right)= \\
& \left\{\mathrm{E}\left(\mathcal{Y} \mid E_{1}=1, E_{0}=1\right)-\mathrm{E}\left(\mathcal{Y} \mid E_{1}=1, E_{0}=0\right)\right\} \operatorname{Pr}\left(E_{0}=0 \mid E_{1}=1\right) .
\end{aligned}
$$


The sign of the bias depends on whether $\mathrm{E}\left(\mathcal{Y} \mid E_{1}=1, E_{0}=1\right)$ is smaller or greater than $\mathrm{E}\left(\mathcal{Y} \mid E_{1}=1, E_{0}=0\right)$, and in principle could go either way, but should be a decreasing function of the proportion of "employment compliers" among "employment compliers" and "always employed", $\operatorname{Pr}\left(E_{0}=0 \mid E_{1}=1\right)$.

\section{Exclusion Restriction}

The exclusion restriction would fail if $Z$, aside from shifting employment deteriorates women's earnings prospect. The literature on the family gap [Waldfogel, 1998] has found that women with children earn lower wages, which could reflect compositional changes among working moms combined with changes in earnings.

In this case, the model in Section 3 could be modified to:

$$
\begin{gathered}
Y=Z \mathcal{Y}_{1}+(1-Z) \mathcal{Y}_{0} \text { if } E=1 \\
E=Z E_{1}+(1-Z) E_{0},
\end{gathered}
$$

where $\mathcal{Y}_{1}$ and $\mathcal{Y}_{0}$ are now the potential wages when $Z$ is externally set to 1 and 0 respectively. Maintaining monotonicity and modifying (AIII) to $Z \Perp\left(\mathcal{Y}_{0}, \mathcal{Y}_{1}, E_{0}, E_{1}\right)$, it can be shown that $\mathrm{E}(Y \mid E=1, Z=1)=\mathrm{E}\left(\mathcal{Y}_{1} \mid E_{1}=1, E_{0}=1\right)$. That is, the instrument still recovers a local measure of wages for "always employed" when $Z$ is set to 1 . If earnings decrease in the presence of a child, $\mathrm{E}(Y \mid E=1, Z=1)$ provides a lower bound for $\mathcal{Y}$ among all "always employed."

\section{Conclusion}

In the early 1970s women started to enter the labor market in terms similar to men: they migrated to "high-powered" professions [Goldin and Katz, 2002] and increased their employment attachment [Goldin, 2006]. Acceptance towards the new role of women in society gained force with female rights movements, and has been corroborated by anti-discrimination laws for equal pay. Taken altogether, women have gradually converged to be as men in the 
workplace, looking for "careers" rather than "jobs," this being part of the larger phenomenon which Claudia Goldin termed as the "quiet revolution" that transformed women's lives.

While improvements in female workforce characteristics have been partially responsible for the closing gender wage gap, selection effects, made evident by the increase in female employment rates, could cast doubts in the relative improvement of women's wages. This paper explores the idea that likely both positive and negative selection rules have guided women's employment decisions. Under unobserved heterogeneity in the selection rule, I show that the usual selection correction procedures might fail to recover the parameters they target, but a local measure of the gender wage gap can still be recovered. The local gap pertains the subpopulation of "always employed" women, and is a relevant comparison group to men, as they exhibit high labor force attachment.

I conclude that the gender wage gap has indeed decreased in the US for this comparable group of men and women, and the reason for the closing gap points to reduced discrimination, rather than composition changes in the "always employed" group. Empirically, I find that the observed (uncorrected) gap provides a good proxy for the local gender wage gap. I do not conclude, however, that selection effects and corrections are unimportant. On the contrary, they are so extreme in the female employment case, which is made evident by the different gap measures estimated in the literature, that a more conservative approach, as proposed in this paper, is called for. In the presence of heterogeneity in selection, focusing on the local gender wage gap is altogether less distorting than usual selection corrections. 


\section{Appendix I: Data}

\section{March CPS}

The Annual Demographic File (ADF) is an annual supplement conducted every March in the CPS survey. It surveys all individuals in the monthly sample, and has detailed demographic information, as well as income and labor force participation in the previous calendar year.

In this paper, I use data from 1976 to 2005. The analysis starts in 1976 because hours worked per week is a categorical variable prior to 1976. I restrict the sample to non-Hispanic whites between ages 25-44, and exclude individuals living in group quarters and the selfemployed. I further eliminate observations with inconsistent reports of weeks worked per

year, hours per week, and annual wages, as well as any allocation for these variables. Hourly wages are generated by dividing annual wages by annual hours (week per year times hours per week), and are deflated by the CPI-U (Consumer Price Index, All Urban Consumers) in the 1982-1984 base. The wage measure used in the paper is the log of hourly wages.

An individual is classified as employed if hourly wage information is available. The full time full year employment sample is further restricted to individuals working more that 35 hours per week and more than 50 week during the year.

Presence of a child younger than 6 is generated from "number of children in family under 6 and is available for both female and male individuals.

The other demographic information in the sample are marital status and education. I classify individuals into five marital status categories - married, widowed, divorced, separated and never married - and four education groups - less than high school (includes some high school), high school graduate, some college, and college graduate or more.

All estimates using the March CPS data employ the March Supplement weight.

\section{June CPS}

The Marriage and Fertility Supplement is conducted on the month of June of the CPS survey in selected years. The questions asked in this supplement vary by survey, but the main fertility variable used in this paper, the year and month of birth of the youngest child, is 
asked in every fertility supplement, and is consistently available for all females of childbearing age (18-44). I use year and month of birth of youngest child to generate indicator variables of presence of young child less than $x$, with $x \in\{1, \ldots, 6\}$.

I follow the same sample delimitation as in the March sample, keeping the non-Hispanic whites between ages 25-44 and excluding individuals living in group quarters and the selfemployed. Wages and employment come from the earner study, which is conducted every month in the CPS sample for the individuals in the outgoing rotation groups (ORG) 4 and 8. Therefore, relative to the ADF file, the sample in the ORG corresponds to one fourth of monthly sample. The earner study has information on weekly wages and hours worked on the jobs individuals hold by the time of the survey. I eliminate individuals with inconsistent reports of weekly earnings and hours per week, as well as any allocation for these two variables. I generate hourly wages by the ratio of weekly earnings and hours per week, and deflate it by the CPI-U. The wage measure is log of hourly wages.

Employment is defined by individuals with hourly wage informations. The full time sample corresponds to those working more than 35 hours per week. Other demographics in the sample are marital status and education. The marital status classification is slightly different from the one used in the ADF sample, due to questionnaire differences, and has four categories: married, spouse absent or separated, widowed or divorced and never married. The education classification is the same as in the ADF sample: less than high school (includes some high school), high school graduate, some college, and college graduate or more.

Since the earner study starts in 1979, this is the first year in my June CPS sample. Survey years included in the sample follow the availability of the Marriage and Fertility Supplement and are 1979-88, 1990, 1992, 1994, 1995, 1998, 2000 and 2002.

All estimates using the June CPS data employ weights from the earner study.

\section{Appendix II: Gender Wage Gap Measures}

This Appendix describes the other estimates of the gender gap pictured in Figures 2 and A.I. 


\section{Observed Gap}

The observed gap was obtained from the following regression:

$$
Y_{i}=\kappa_{0 x t}+\kappa_{1 x t} * G_{i}+u_{i}
$$

where $x$ again subscripts four education categories: less than high school (includes some high school), high school graduate, some college, and college graduate or more. $\kappa_{1 x t}$ correspond to education specific gaps, and the observed gap in period $t$ is recovered by weighting $\kappa_{1 x t}$ by female education proportions in each time period.

\section{Parametric Correction}

The gap obtained from the parametric selection model is estimated in two stages. The first stage estimates a participation probit for the female population:

$$
\operatorname{Pr}(E=1 \mid T=t, X, G=1)=\Phi\left(\alpha_{t}^{\prime} X_{i}+\gamma_{t} Z_{i}\right)
$$

where $X_{i}$ is a vector with education dummies and $Z_{i}$ indicates the presence of a child less than 6 . The above results is used to construct the mills ratio, $\lambda_{i}=\lambda\left(\hat{\alpha}_{t} X_{i}+\hat{\gamma}_{t} Z_{i}\right)$, and the second stage regression includes $\lambda_{i} * G_{i}$ as a control for the female selection bias:

$$
Y_{i}=\theta_{0 x t}+\theta_{1 x t} * G_{i}+\theta_{2 x t} \lambda_{i} * G_{i}+u_{i}
$$

$\theta_{1 x t}$ is weighted by female education proportions in each time period. 


\section{Bounds on Mean and Median Wages (referenced in Section 2.3)}

When an instrument is available (and maintaining the assumption $\mathcal{Y}$ has a bounded support), we can use condition $\mathrm{E}(\mathcal{Y})=\mathrm{E}(\mathcal{Y} \mid Z)$ to restate $(2)$ as:

$$
\begin{aligned}
\max _{Z}\{\mathrm{E}(Y \mid E=1, Z) \operatorname{Pr}(E=1 \mid Z)+\underline{\mathcal{Y}} \operatorname{Pr}(E=0 \mid Z)\} \\
\leq \mathrm{E}(\mathcal{Y}) \leq \min _{Z}\{\mathrm{E}(Y \mid E=1, Z) \operatorname{Pr}(E=1 \mid Z)+\overline{\mathcal{Y}} \operatorname{Pr}(E=0 \mid Z)\}
\end{aligned}
$$

where I have abstracted from $X$ and $G$. That is, $Z$ shifts participation in a manner that is unrelated to the measure of wages, making it valid to consider the best bounds under each value of $Z$.

Positive selection - $\mathrm{E}(Y \mid E=1) \geq \mathrm{E}(\mathcal{Y} \mid E=0)$ - implies $\mathrm{E}(\mathcal{Y}) \geq \mathrm{E}(Y \mid E=1)$, which can be seen by simple manipulation of (1). Substituting this tighter upper bound to (A.4) delivers:

$$
\begin{aligned}
\max _{Z}\{\mathrm{E}(Y \mid E=1, Z) \operatorname{Pr}(E=1 \mid Z)+\underline{\mathcal{Y}} \operatorname{Pr}(E=0 \mid Z)\} & \\
& \leq \mathrm{E}(\mathcal{Y}) \leq \min _{Z}\{\mathrm{E}(Y \mid E=1, Z)\} .
\end{aligned}
$$

Similarly, under negative selection:

$$
\begin{aligned}
\max _{Z}\{\mathrm{E}(Y \mid E=1, Z)\} \leq \mathrm{E}(\mathcal{Y}) \leq \\
\min _{Z}\{\mathrm{E}(Y \mid E=1, Z) \operatorname{Pr}(E=1 \mid Z)+\overline{\mathcal{Y}} \operatorname{Pr}(E=0 \mid Z)\} .
\end{aligned}
$$

I estimate each quantity in (A.4), (A.5) and (A.6) by its sample counterpart, taking $\mathcal{Y}$ and $\overline{\mathcal{Y}}$ to the minimum and maximum of observed wages.

Moving away from the assumption of bounded support, I estimate bounds on median wage following a procedure similar to the one outlined in Blundell et al. [2007]. The starting 
point is the CDF of wages $F(\mathcal{Y})$ which is itself bounded by 0 and 1 :

$$
\begin{aligned}
\max _{Z}\{F(Y \mid E=1, Z) \operatorname{Pr}(E= & 1 \mid Z)\} \leq F(\mathcal{Y}) \leq \\
& \min _{Z}\{F(Y \mid E=1, Z) \operatorname{Pr}(E=1 \mid Z)+\operatorname{Pr}(E=0 \mid Z)\} .
\end{aligned}
$$

Let $Z^{\prime}\left(Z^{\prime \prime}\right)$ denote the argmax (argmin) of above lower (upper) bound. Bounds on median wages are given by:

$$
Y^{l} \leq \operatorname{Med}(\mathcal{Y}) \leq Y^{u}
$$

where $Y^{l}$ and $Y^{u}$ solve the $q^{l}$ and $q^{u}$ quantiles of $F\left(. \mid E=1, Z^{\prime \prime}\right)$ and $F\left(. \mid E=1, Z^{\prime}\right)$ with:

$$
q^{l}=\frac{0.5-\operatorname{Pr}\left(E=0 \mid Z^{\prime \prime}\right)}{\operatorname{Pr}\left(E=1 \mid Z^{\prime \prime}\right)} \quad \text { and } \quad q^{u}=\frac{0.5}{\operatorname{Pr}\left(E=1 \mid Z^{\prime}\right)}
$$

Positive and negative selection assumptions change upper and lower bounds of (A.7) in the same spirit as they change bounds for $\mathrm{E}(\mathcal{Y})$. Under positive selection, wages for those observed working stochastically dominate those on non workers and $F(Y \mid E=1) \leq$ $F(\mathcal{Y} \mid E=0)$. Thus, lower bound in (A.7) is tightened to $\max _{Z} F(Y \mid E=1, Z)$. Similarly, under negative selection upper bound in (A.7) becomes $\min _{Z} F(Y \mid E=1, Z)$. I estimate each quantity in (A.7) and (A.9) by its sample counterpart and use the observed distribution of $Y \mid E=1, Z$ when searching for quantiles.

Two features of the bounding procedure on median wages are worth noting. First, when the exclusion restriction is invalid, upper and lower limits in (A.8) may cross. In the case the instrument is valid, but sign of selection is incorrectly imposed, bounds may also cross, as seen in the example with simulated data, where the exclusion restriction is combined with the negative selection assumption. Second, the quantiles $q^{l}$ and $q^{u}$ can only be computed when participation is above $50 \%$. For example, estimation of (A.9) requires that $\operatorname{Pr}(E=$ $\left.0 \mid Z^{\prime \prime}\right) \leq 0.5$ and that $\operatorname{Pr}\left(E=1 \mid Z^{\prime}\right) \geq 0.5$. 


\section{Blundell et al. [2007] Bounds using US Data (referenced in Section 4.3)}

I follow the approach in Blundell et al. [2007] and construct bounds on the median gender wage gap using US data, with sample delimitation for the March CPS data as described in Appendix I. Participation is defined by any employment ${ }^{14}$, and conditioning covariates are time $T$, education $X$ and age $A$. I let $T$ denote the start and end of my sample, $t_{1}=1976-1980$ and $t_{2}=2001-2005, X$, the four education categories and $A$, five year age groups (25-29, 30$34,35-39,40-44)$. The parameter of interest is the improvement of the gender gap between 1976-1980 and 2001-2005, and is given by:

$$
\begin{aligned}
\Delta\left(t_{2}, X, A\right)-\Delta\left(t_{1}, X, A\right) & =\left\{\operatorname{Med}\left(\mathcal{Y} \mid t_{2}, X, A, G=1\right)-\operatorname{Med}\left(\mathcal{Y} \mid t_{2}, X, A, G=0\right)\right\} \\
& -\left\{\operatorname{Med}\left(\mathcal{Y} \mid t_{1}, X, A, G=1\right)-\operatorname{Med}\left(\mathcal{Y} \mid t_{1}, X, A, G=0\right)\right\} .
\end{aligned}
$$

Bounds on each quantity of (A.10) are estimated following the procedure outlined in the previous section of this Appendix, where I consider four scenarios. The baseline result are bounds on $\Delta\left(t_{2}, X, A\right)-\Delta\left(t_{1}, X, A\right)$ that impose neither the exclusion restriction nor the sign of average selection. The second scenario imposes positive selection for both men and women, and for both time periods. The third uses the exclusion restriction, the presence of a child less than six years old, in the computation of female median wages, with no restrictions on the sign of average selection for both men and women. Finally, the fourth case combines the exclusion restriction for women with positive selection for both genders.

Results on $\Delta\left(t_{2}, X, A\right)-\Delta\left(t_{1}, X, A\right)$ are summarized by education categories using the "additivity" assumption of Blundell et al. [2007], in which changes in education differentials across time are assumed to be the same for all age groups, making it valid to search across

\footnotetext{
${ }^{14}$ Full time work rate is below $50 \%$ for women in start of sample period, and bounds on $\operatorname{Med}(\mathcal{Y})$ cannot be recovered.
} 
$A$ for the best values of $\Delta\left(t_{2}, X, A\right)-\Delta\left(t_{1}, X, A\right)$. That is:

$$
\begin{aligned}
\max _{A} L B\left\{\Delta\left(t_{2}, X, A\right)-\Delta\left(t_{1}, X, A\right)\right\} \leq \Delta\left(t_{2}, X\right)-\Delta\left(t_{1}, X\right) \leq \\
\min _{A} U B\left\{\Delta\left(t_{2}, X, A\right)-\Delta\left(t_{1}, X, A\right)\right\}
\end{aligned}
$$

where LB and UB stand for lower and upper bounds. Results are displayed in Figure A.I. The baseline case is uninformative about the evolution of the gap for all education categories. For those with some college, for example, the gender gap could have improved as much as $.52 \log$ points or deteriorated by 0.21 log points. The positive selection assumption is shown to be quite crucial to sign the evolution of the gap: all individuals with high school degrees or more experience a substantial improvement in gap under this assumption. The exclusion restriction alone is barely able to sign changes in gap (only for individuals with a college degree or more), even when abstracting from sample variability. Finally, the combination of the exclusion restriction and positive selection is not valid, as bounds for those with some college and more than college cross. 


\section{References}

Joshua D. Angrist. Conditioning on the probability of selection to control selection bias. Technical Working Paper 0181, National Bureau of Economic Research, June 1995. URL http://www .nber .org/papers/t0181.

Joshua D. Angrist and William Evans. Children and their parents labor supply: Evidence from exogenous variation in family size. American Economic Review, 88(3):450-477, June 1998.

Joshua D. Angrist, Guido D. Imbens, and Donald B. Rubin. Identification of causal effects using instrumental variables. Journal of the American Statistical Association, 91(434): 444-454, June 1996.

Francine Blau and Lawrence Kahn. The us gender pay gap in the 1990s: Slowing convergence. Industrial and Labor Relations Review, 60(1):45-66, 2006.

Richard Blundell, Amanda Gosling, Hidehiko Ichimura, and Costas Meghir. Changes in the distribution of female and male wages accounting for employment composition using bounds. Econometrica, 75(2):323-363, March 2007.

Martin Browning. Children and household economic behavior. Journal of Economic Literature, 30(3):1434-1475, September 1992.

David Card. The effect of unions on the wage structure of wages: A longitudinal analysis. Econometrica, 64(4):957-979, July 1996.

Claudia Goldin. The quiet revolution that tranformed women's employment, education, and family. AEA Papers and Proceedings, Richard T. Ely Lecture, 92(2):1-21, 2006.

Claudia Goldin and Lawrence F. Katz. The power of the pill: Oral contraceptives and women's career and marriage decisions. Journal of Political Economy, 110(4):730-770, August 2002. 
Reuben Gronau. Wage comparison - a selectivity bias. Journal of Political Economy, 82(6): 1119-1143, 1974.

James Heckman. Shadow price, market wages, and labor supply. Econometrica, 42(4): 679-694, July 1974.

James Heckman. Varieties of selection bias. American Economic Review Papers and Proceedings, 80(2):313-318, May 1990.

Guido D. Imbens and Joshua D. Angrist. Identification and estimation of local average treatment effects. Econometrica, 62(2):467-475, March 1994.

William Johnson, Yuichi Kitamura, and Derek Neal. Evaluating a simple method for estimating black-white gaps in median wages. American Economic Review Papers and Proceedings, 90(2):339-343, May 2000.

David Lee. Training, wages, and sample selection: Estimating sharp bounds on treatment effects. Review of Economic Studies, 76(3):1071-1102, June 2009.

Brigitte C. Madrian and Lars John Lefgren. A note on longitudinally matching Current Population Survey (CPS) respondents. Working Paper 247, National Bureau of Economic Research, November 1999. URL http://www.nber.org/papers/t0247.

Charles Manski. Nonparametric bounds on treatment effects. The American Economic Review Papers and Proceedings, 80(2):319-323, 1990.

Robert Moffit. New developments in econometric methods for labor market analysis. In O. Ashenfelter and D. Card, editors, Handbook of Labor Economics, pages 1367-1397. Elsevier, 1999.

Casey Mulligan and Yona Rubinstein. Selection, investment and women's relative wage over time. Quarterly Journal of Economics, 123(3):1061-1110, August 2008.

Derek Neal. The measured black-white wage gap among women is too small. Journal of Political Economy, 112(1):S1-S28, 2004. 
Derek A. Neal and William R. Johnson. The role of pre-market factors in black-white wage differences. Journal of Political Economy, 104(5):869-895, October 1996.

Claudia Olivetti and Barbara Petrongolo. Unequal pay or unequal employment? a crosscountry analysis of gender gaps. Journal of Labor Economics, 26(4):621-654, 2008.

Donald Rubin. Estimating causal effects of treatments in randomized and non-randomized studies. Journal of Educational Psycology, 66(5):688-701, October 1974.

Francis Vella. Models with sample selection bias: A survey. Journal of Human Resources, 127-169(33):1, Winter 1998.

Edward Vytlacil. Independence, monotonicity and latent index models: An equivalence result. Econometrica, 70(1):331-341, January 2002.

Jane Waldfogel. Understanding the "family gap' in pay for women with children. Journal of Economic Perspectives, 12(1):137-156, Winter 1998.

Robert Willis. What have we learned from the economics of the family? American Economic Review, 77(2):68-81, May 1987.

Junni L. Zhang, Donald B. Rubin, and Fabrizia Mealli. Evaluating the effects of job training programs on wages through principal stratification. volume 21 of Advances in Econometrics, pages 117-145. Emerald Group Publishing Limited, 2008. 
Table 1: Simulated Data

\begin{tabular}{|c|c|c|}
\hline \multicolumn{2}{|l|}{ Panel A: Summary of Observed Data } & $90 \% \mathrm{CI}$ \\
\hline $\mathrm{E}(Y \mid E=1)$ & 1.596 & $(1.560,1.630)$ \\
\hline $\mathrm{E}(Y \mid E=1, Z=1)$ & 2.468 & $(2.404,2.528)$ \\
\hline $\mathrm{E}(Y \mid E=1, Z=0)$ & 1.280 & $(1.241,1.320)$ \\
\hline $\operatorname{Pr}(E=1)$ & 0.500 & $(0.492,0.507)$ \\
\hline $\operatorname{Pr}(E=1 \mid Z=1)$ & 0.265 & $(0.256,0.275)$ \\
\hline $\operatorname{Pr}(E=1 \mid Z=0)$ & 0.734 & $(0.724,0.745)$ \\
\hline \multicolumn{3}{|l|}{ Panel B: Summary by Type } \\
\hline $\mathrm{E}(\mathcal{Y})$ & 1.595 & $(1.569,1.623)$ \\
\hline $\operatorname{Med}(\mathcal{Y})$ & 1.465 & $(1.432,1.496)$ \\
\hline $\mathrm{E}(\mathcal{Y} \mid \mathrm{N})$ & 1.595 & $(1.559,1.633)$ \\
\hline $\mathrm{E}(\mathcal{Y} \mid \mathrm{P})$ & 1.595 & $(1.560,1.632)$ \\
\hline $\operatorname{Pr}(E=1 \mid \mathrm{N})$ & 0.234 & $(0.224,0.244)$ \\
\hline $\operatorname{Pr}(E=1 \mid \mathrm{P})$ & 0.765 & $(0.756,0.775)$ \\
\hline $\mathrm{E}(\mathcal{Y} \mid E=1, \mathrm{~N})$ & 0.605 & $(0.552,0.657)$ \\
\hline $\mathrm{E}(\mathcal{Y} \mid E=0, \mathrm{~N})$ & 1.898 & $(1.855,1.940)$ \\
\hline $\mathrm{E}(\mathcal{Y} \mid E=1, \mathrm{P})$ & 1.899 & $(1.858,1.941)$ \\
\hline $\mathrm{E}(\mathcal{Y} \mid E=0, \mathrm{P})$ & 0.604 & $(0.551,0.657)$ \\
\hline \multicolumn{3}{|c|}{ Panel C: Summary by Potential Response } \\
\hline $\mathrm{E}\left(\mathcal{Y} \mid E_{1}=0, E_{0}=0\right)$ & 2.467 & $(2.422,2.510)$ \\
\hline $\mathrm{E}\left(\mathcal{Y} \mid E_{1}=0, E_{0}=1\right)$ & 0.605 & $(0.579,0.629)$ \\
\hline $\mathrm{E}\left(\mathcal{Y} \mid E_{1}=1, E_{0}=1\right)$ & 2.467 & $(2.424,2.510)$ \\
\hline $\operatorname{Pr}\left(E_{1}=0, E_{0}=0\right)$ & 0.266 & $(0.258,0.274)$ \\
\hline $\operatorname{Pr}\left(E_{1}=1, E_{0}=0\right)$ & 0.468 & $(0.460,0.477)$ \\
\hline $\operatorname{Pr}\left(E_{1}=1, E_{0}=1\right)$ & 0.266 & $(0.259,0.273)$ \\
\hline \multicolumn{3}{|l|}{ Panel D: Estimation } \\
\hline Parametric Estimator of $\mathrm{E}(\mathcal{Y})^{\mathrm{a}}$ & 0.605 & $(0.518,0.688)$ \\
\hline LB on $\mathrm{E}(\mathcal{Y})$ & 0.119 & $(-0.060,0.261)$ \\
\hline UB on $\mathrm{E}(\mathcal{Y})$ & 3.229 & $(2.966,3.571)$ \\
\hline UB on $\mathrm{E}(\mathcal{Y})$, Positive Selection ${ }^{\mathrm{b}}$ & 1.280 & $(1.241,1.320)$ \\
\hline LB on $\mathrm{E}(\mathcal{Y})$, Negative Selection ${ }^{\mathrm{c}}$ & 2.468 & $(2.404,2.528)$ \\
\hline $\operatorname{LB}$ on $\operatorname{Med}(\mathcal{Y})$ & 0.501 & $(0.441,0.562)$ \\
\hline UB on $\operatorname{Med}(\mathcal{Y})$ & 1.825 & $(1.756,1.897)$ \\
\hline UB on $\operatorname{Med}(\mathcal{Y})$, Posit & 1.129 & $(1.086,1.179)$ \\
\hline LB on $\operatorname{Med}(\mathcal{Y})$, Negative Selection & 2.367 & $(2.289,2.444)$ \\
\hline Reduced Form on $\mathrm{Z}^{\mathrm{e}}$ & 2.468 & $(2.404,2.528)$ \\
\hline
\end{tabular}

Data generated from 1,000 replications the model in (4) and (6) with 10,000 observations each. The parametric selection estimator of $\mathrm{E}(\mathcal{Y})$ corresponds to the constant of a regression that includes the mills ratio, generated from a first stage probit of $E$ on $Z$, as a control. UB and LB abbreviate upper and lower bound. The construction of the bounds are detailed in Appendix II. The reduced form on $Z$ entry in Panel D sums of the constant and coefficient in a regression where $Z$ enters as the only explanatory variable. ${ }^{\mathrm{a}, \mathrm{b}, \mathrm{c}}$ : mean squared error with respect to $\mathrm{E}(\mathcal{Y})$ are $0.981(0.818,1.158), 0.100(0.079,0.122)$, and 0.760 $(0.661,0.870)$, respectively. ${ }^{\mathrm{d}}$ : mean squared error with respect to $\operatorname{Med}(\mathcal{Y})$ is $0.112(0.086,0.141)$. ${ }^{\text {e: }}$ mean squared error with respect to $\mathrm{E}\left(\mathcal{Y} \mid E_{1}=1, E_{0}=1\right)$ is $0.001(0.000,0.003)$. 
Table 2: Summary Statistics March CPS (means)

\begin{tabular}{|c|c|c|c|c|c|c|}
\hline & \multicolumn{3}{|c|}{ Female } & \multicolumn{3}{|c|}{ Male } \\
\hline & $1976-2005$ & $1976-80$ & $2001-05$ & $1976-2005$ & $1976-80$ & $2001-05$ \\
\hline$\%$ married & 0.709 & 0.791 & 0.671 & 0.666 & 0.776 & 0.616 \\
\hline$\%$ widowed & 0.00905 & 0.0102 & 0.00873 & 0.00221 & 0.00171 & 0.00286 \\
\hline$\%$ divorced & 0.114 & 0.0910 & 0.118 & 0.0868 & 0.0593 & 0.0916 \\
\hline$\%$ separated & 0.0278 & 0.0260 & 0.0243 & 0.0192 & 0.0178 & 0.0171 \\
\hline$\%$ never married & 0.140 & 0.0819 & 0.178 & 0.226 & 0.145 & 0.273 \\
\hline$\%$ less than hs & 0.0901 & 0.162 & 0.0549 & 0.0960 & 0.147 & 0.0704 \\
\hline$\%$ hs grad & 0.381 & 0.466 & 0.284 & 0.350 & 0.361 & 0.317 \\
\hline$\%$ some college & 0.257 & 0.181 & 0.307 & 0.245 & 0.204 & 0.276 \\
\hline$\%$ college or more & 0.273 & 0.191 & 0.354 & 0.309 & 0.288 & 0.336 \\
\hline number children $\leq 6$ & 0.421 & 0.457 & 0.408 & 0.409 & 0.477 & 0.383 \\
\hline$\%$ no child $\leq \overline{6}$ & 0.689 & 0.659 & 0.702 & 0.704 & 0.650 & 0.725 \\
\hline$\% 1$ child $\leq 6$ & 0.214 & 0.238 & 0.202 & 0.197 & 0.238 & 0.180 \\
\hline$\% 2$ children $\leq 6$ & 0.0853 & 0.0900 & 0.0836 & 0.0867 & 0.0987 & 0.0825 \\
\hline$\% 3+$ children $\leq 6$ & 0.0119 & 0.0125 & 0.0123 & 0.0124 & 0.0135 & 0.0122 \\
\hline \% employed & 0.763 & 0.648 & 0.795 & 0.946 & 0.965 & 0.931 \\
\hline $\ln$ (hourly wage) & 1.861 & 1.726 & 2.022 & 2.206 & 2.245 & 2.278 \\
\hline$\%$ employed $\mathrm{w} / \mathrm{o}$ child $\leq 6$ & 0.822 & 0.737 & 0.841 & 0.934 & 0.955 & 0.915 \\
\hline$\%$ employed $\mathrm{w} /$ child $\leq 6$ & 0.632 & 0.477 & 0.686 & 0.975 & 0.984 & 0.972 \\
\hline$\%$ full time & 0.444 & 0.304 & 0.511 & 0.764 & 0.758 & 0.782 \\
\hline $\ln ($ hourly wage $)$ & 1.970 & 1.851 & 2.081 & 2.267 & 2.296 & 2.323 \\
\hline$\% \mathrm{ft}$ w $/ \mathrm{o}$ child $\leq 6$ & 0.522 & 0.391 & 0.581 & 0.738 & 0.732 & 0.753 \\
\hline$\% \mathrm{ft} w /$ child $\leq 6$ & 0.271 & 0.137 & 0.347 & 0.825 & 0.806 & 0.858 \\
\hline observations & 469050 & 67813 & 92418 & 419208 & 59052 & 81639 \\
\hline
\end{tabular}

Data: March CPS, ADF, 1976-2005. Sample restricted to white non-Hispanic individuals between ages 25 and 44 . An individual is categorized as employed if it reports any wage in previous year. Full time workers are the employed individuals who have worked 50 or more weeks, and 35 or more hours per week, in previous year. Wages are log horly wages deflated by the CPI-U, in the 1982-1984 base. More details on sample delimitation are contained in Appendix I. \% indicates the mean of a binary variable. All means are computed using the March Supplement weight. 
Table 3: Summary Statistics June CPS (means)

\begin{tabular}{|c|c|c|c|c|c|c|}
\hline & \multicolumn{3}{|c|}{ Female } & \multicolumn{3}{|c|}{ Male } \\
\hline & 1979-2002 & 1979-1982 & 1994-2002 & 1979-2002 & 1979-1982 & 1994-2002 \\
\hline$\%$ married & 0.710 & 0.758 & 0.671 & 0.675 & 0.730 & 0.627 \\
\hline$\%$ absent or separated & 0.0360 & 0.0345 & 0.0377 & 0.0249 & 0.0248 & 0.0287 \\
\hline$\%$ widowed or divorced & 0.124 & 0.115 & 0.128 & 0.0859 & 0.0751 & 0.0942 \\
\hline$\%$ never married & 0.130 & 0.0933 & 0.163 & 0.214 & 0.170 & 0.250 \\
\hline$\%$ less than hs & 0.105 & 0.143 & 0.0763 & 0.108 & 0.140 & 0.0842 \\
\hline$\%$ hs grad & 0.413 & 0.477 & 0.323 & 0.365 & 0.373 & 0.337 \\
\hline$\%$ some college & 0.244 & 0.190 & 0.310 & 0.229 & 0.196 & 0.273 \\
\hline$\%$ college or more & 0.238 & 0.190 & 0.291 & 0.298 & 0.290 & 0.306 \\
\hline$\%$ any child $\leq 6$ & 0.325 & 0.339 & 0.324 & . & 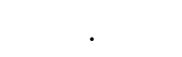 & . \\
\hline$\%$ any child $\leq 5$ & 0.279 & 0.291 & 0.274 & . & . & . \\
\hline$\%$ any child $\leq 4$ & 0.233 & 0.244 & 0.228 & . & $\cdot$ & e \\
\hline$\%$ any child $\leq 3$ & 0.180 & 0.190 & 0.177 & . & . & $\cdot$ \\
\hline$\%$ any child $\leq 2$ & 0.124 & 0.130 & 0.122 & . & 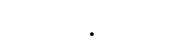 & . \\
\hline$\%$ any child $\leq 1$ & 0.0629 & 0.0660 & 0.0623 & . & . & . \\
\hline$\%$ full time & 0.442 & 0.374 & 0.474 & 0.796 & 0.799 & 0.780 \\
\hline $\ln$ (hourly wage) & 1.928 & 1.871 & 1.980 & 2.195 & 2.224 & 2.184 \\
\hline$\% \mathrm{ft}$ w $/ \mathrm{o}$ child $\leq 6$ & 0.522 & 0.458 & 0.551 & . & . & . \\
\hline$\% \mathrm{ft} w /$ child $\leq 6$ & 0.275 & 0.208 & 0.313 & . & - & . \\
\hline$\% \mathrm{ft}$ w $/ \mathrm{o}$ child $\leq 5$ & 0.509 & 0.445 & 0.537 & . & . & . \\
\hline$\%$ ft $\mathrm{w} /$ child $\leq 5$ & 0.268 & 0.199 & 0.307 & . & . & . \\
\hline$\% \mathrm{ft}$ w $/ \mathrm{o}$ child $\leq 4$ & 0.497 & 0.432 & 0.526 & . & . & . \\
\hline$\%$ ft $\mathrm{w} /$ child $\leq 4$ & 0.259 & 0.191 & 0.297 & . & . & . \\
\hline$\% \mathrm{ft}$ w/o child $\leq 3$ & 0.484 & 0.419 & 0.513 & . & . & . \\
\hline$\% \mathrm{ft} \mathrm{w} /$ child $\leq 3$ & 0.250 & 0.179 & 0.291 & . & . & . \\
\hline$\% \mathrm{ft}$ w/o child $\leq 2$ & 0.471 & 0.405 & 0.502 & . & . & r. \\
\hline$\%$ ft $\mathrm{w} /$ child $\leq 2$ & 0.234 & 0.161 & 0.272 & . & . & \\
\hline$\% \mathrm{ft} w / 0$ child $\leq 1$ & 0.456 & 0.389 & 0.488 & . & . & \\
\hline$\% \mathrm{ft}$ w $/$ child $\leq 1$ & 0.226 & 0.159 & 0.263 & . & $\cdot$ & . \\
\hline observations & 59270 & 14689 & 14697 & 50826 & 12238 & 13006 \\
\hline
\end{tabular}

Data: June CPS, 1979-2002. Sample restricted to white non-Hispanic individuals between ages 25 and 44 . An individual is categorized as employed if holding a job by the time of the survey. Full time workers are the employed individuals who work more than 35 hours per week. Wages are log horly wages deflated by the CPI-U, in the 1982-1984 base. Age of youngest child is computed using the birth month and birth year of the child available in the fertility supplement. More details on sample delimitation are contained in Appendix I. \% indicates the mean of a binary variable. All means are computed using weights from the earner study. 
Table 4: Changes in Female Employment Induced by the Presence of Any Child $\leq 6$

\begin{tabular}{|c|c|c|c|c|}
\hline \multicolumn{5}{|l|}{$\begin{array}{l}\text { Entries in each triplet are: } \\
\left(\Psi_{x t(G=1)}, N_{x t}, \% E_{x t}\right)\end{array}$} \\
\hline$x \backslash t$ & $\begin{array}{c}(1) \\
1976-80\end{array}$ & $\begin{array}{c}(2) \\
2001-05\end{array}$ & $\begin{array}{c}(3) \\
1976-80\end{array}$ & $\begin{array}{c}(4) \\
2001-05\end{array}$ \\
\hline less than high school & $\begin{array}{c}-0.197^{* * *} \\
10759 \\
0.517\end{array}$ & $\begin{array}{c}-0.133^{* * *} \\
4831 \\
0.583\end{array}$ & $\begin{array}{c}-0.137^{* * *} \\
10759 \\
0.193\end{array}$ & $\begin{array}{c}-0.162^{* * *} \\
4831 \\
0.315\end{array}$ \\
\hline high school graduate & $\begin{array}{c}-0.258^{* * *} \\
31448 \\
0.630\end{array}$ & $\begin{array}{c}-0.150^{* * *} \\
27025 \\
0.761\end{array}$ & $\begin{array}{c}-0.236^{* * *} \\
31448 \\
0.292\end{array}$ & $\begin{array}{c}-0.215^{* * *} \\
27025 \\
0.482\end{array}$ \\
\hline some college & $\begin{array}{c}-0.285^{* * *} \\
12551 \\
0.680\end{array}$ & $\begin{array}{c}-0.161^{* * *} \\
29395 \\
0.812\end{array}$ & $\begin{array}{c}-0.294^{* * *} \\
12551 \\
0.322\end{array}$ & $\begin{array}{c}-0.243^{* * *} \\
29395 \\
0.514\end{array}$ \\
\hline college or more & $\begin{array}{c}-0.316^{* * *} \\
13055 \\
0.774\end{array}$ & $\begin{array}{c}-0.186^{* * *} \\
31167 \\
0.841\end{array}$ & $\begin{array}{c}-0.372^{* * *} \\
13055 \\
0.411\end{array}$ & $\begin{array}{c}-0.275^{* * *} \\
31167 \\
0.563\end{array}$ \\
\hline pooled (all education groups) ${ }^{\dagger}$ & $\begin{array}{c}-0.273^{* * *} \\
67813 \\
0.648\end{array}$ & $\begin{array}{c}-0.166^{* * *} \\
92418 \\
0.795\end{array}$ & $\begin{array}{c}-0.258^{* * *} \\
67813 \\
0.304\end{array}$ & $\begin{array}{c}-0.244^{* * *} \\
92418 \\
0.511\end{array}$ \\
\hline
\end{tabular}

Data: March CPS, ADF, 1976-2005. Sample delimitation is as in notes to Table 2, with further details in Appendix I. Each triplet refers to an education $(x)$ and time $(t)$ specific sample. The entries are, respectively, the change in probability $\Psi_{x t(G=1)}$ as in defined in equation (8), the number of observations, and the average employment rate. The instrument $Z$ is an indicator for the presence of child younger that six. $\dagger$ controls for education specific employment rates. $* * *$ denotes statistical significance at the $1 \%$ level. 
Table 5: Wage Gap between Men and "Always Employed" Women, by Education

\begin{tabular}{lcccc}
\hline \hline & \multicolumn{2}{c}{$E:$ Any Employment } & \multicolumn{2}{c}{$E:$ Full Time, Full Year } \\
& $(1)$ & $(2)$ & $(3)$ & $(4)$ \\
& $1976-80$ & $2001-05$ & $1976-80$ & $2001-05$ \\
Panel A: Less than High School & & & & \\
\hline female, (a) & $-0.572^{* * *}$ & $-0.326^{* * *}$ & $-0.502^{* * *}$ & $-0.306^{* * *}$ \\
& $(0.013)$ & $(0.021)$ & $(0.016)$ & $(0.021)$ \\
female* $Z$, (b) & $-0.048^{*}$ & -0.058 & -0.036 & -0.043 \\
& $(0.026)$ & $(0.039)$ & $(0.038)$ & $(0.048)$ \\
constant & $2.015^{* * *}$ & $1.819^{* * *}$ & $2.063^{* * *}$ & $1.858^{* * *}$ \\
& $(0.008)$ & $(0.012)$ & $(0.008)$ & $(0.012)$ \\
\hline $\mathrm{R}^{2}$ & 0.178 & 0.058 & 0.157 & 0.065 \\
$\mathrm{~N}$ & 13298 & 7249 & 7231 & 4665 \\
Local Gap, (a)+(b) & -0.620 & -0.384 & -0.538 & -0.349 \\
& $(0.025)$ & $(0.037)$ & $(0.037)$ & $(0.046)$ \\
Observed (Uncorrected) Gap & -0.582 & -0.337 & -0.507 & -0.312 \\
\hline \multirow{2}{*}{ Panel B: High School Graduate } & & & & \\
\hline female, (a) & $-0.562^{* * *}$ & $-0.300^{* * *}$ & $-0.459^{* * *}$ & $-0.262^{* * *}$ \\
& $(0.007)$ & $(0.008)$ & $(0.007)$ & $(0.008)$ \\
female* $Z$, (b) & $-0.077^{* * *}$ & $-0.037^{* * *}$ & $-0.099^{* * *}$ & $-0.039^{* *}$ \\
& $(0.011)$ & $(0.013)$ & $(0.014)$ & $(0.016)$ \\
constant & $2.225^{* * *}$ & $2.069^{* * *}$ & $2.250^{* * *}$ & $2.106^{* * *}$ \\
& $(0.004)$ & $(0.005)$ & $(0.004)$ & $(0.004)$ \\
\hline R ${ }^{2}$ & 0.210 & 0.062 & 0.199 & 0.058 \\
Local Gap, (a)+(b) & 40811 & 45127 & 25420 & 33161 \\
& -0.639 & -0.337 & -0.557 & -0.301 \\
\hline \hline & $(0.011)$ & $(0.012)$ & $(0.014)$ & $(0.015)$ \\
& -0.581 & -0.308 & -0.475 & -0.269 \\
\hline
\end{tabular}

continued on next page 
continued from previous page (Table 5)

\begin{tabular}{lcccc}
\hline \hline & \multicolumn{2}{c}{$E:$ Any Employment } & \multicolumn{2}{c}{ E: Full Time, Full Year } \\
& $(1)$ & $(2)$ & $(3)$ & $(4)$ \\
& $1976-80$ & $2001-05$ & $1976-80$ & $2001-05$ \\
Panel C: Some College & & & & \\
\hline female, (a) & $-0.424^{* * *}$ & $-0.278^{* * *}$ & $-0.384^{* * *}$ & $-0.255^{* * *}$ \\
& $(0.010)$ & $(0.007)$ & $(0.010)$ & $(0.008)$ \\
female* $Z$, (b) & $-0.105^{* * *}$ & -0.013 & $-0.144^{* * *}$ & $-0.027^{* *}$ \\
& $(0.020)$ & $(0.011)$ & $(0.028)$ & $(0.012)$ \\
constant & $2.239^{* * *}$ & $2.224^{* * *}$ & $2.295^{* * *}$ & $2.262^{* * *}$ \\
& $(0.005)$ & $(0.005)$ & $(0.005)$ & $(0.005)$ \\
\hline $\mathrm{R}^{2}$ & 0.129 & 0.053 & 0.132 & 0.058 \\
Obs & 20405 & 45847 & 13356 & 33278 \\
Local Gap, (a)+(b) & -0.529 & -0.290 & -0.528 & -0.282 \\
& $(0.019)$ & $(0.011)$ & $(0.027)$ & $(0.012)$ \\
Observed (Uncorrected) Gap & -0.453 & -0.281 & -0.407 & -0.261 \\
\hline \multirow{2}{*}{ Panel D: College or More } & & & & \\
\hline female, (a) & & & & \\
female* $Z$, (b) & $-0.365^{* * *}$ & $-0.281^{* * *}$ & $-0.361^{* * *}$ & $-0.276^{* * *}$ \\
& $(0.008)$ & $(0.008)$ & $(0.009)$ & $(0.008)$ \\
constant & $-0.051^{* * *}$ & $0.109^{* * *}$ & $-0.049^{* *}$ & $0.074^{* * *}$ \\
& $(0.016)$ & $(0.010)$ & $(0.021)$ & $(0.012)$ \\
\hline $\mathrm{R}^{2}$ & $2.382^{* * *}$ & $2.586^{* * *}$ & $2.437^{* * *}$ & $2.618^{* * *}$ \\
Obs & $(0.005)$ & $(0.005)$ & $(0.005)$ & $(0.005)$ \\
Local Gap, (a)+(b) & 0.095 & 0.036 & 0.102 & 0.042 \\
& 26844 & 52170 & 19287 & 39848 \\
Observed (Uncorrected) Gap & -0.416 & -0.173 & -0.409 & -0.202 \\
\hline \hline
\end{tabular}

Data: March CPS, ADF, 1976-2005. Sample delimitation is as in notes to Table 2, with further details in Appendix I. Regression results from equation (9), stratified by education, time and participation (any employment and full time, full year). Standard errors in parenthesis. The measured gap is obtained by a wage regression that includes a gender dummy as explanatory variable. *** denotes statistical significance at the $1 \%$ level. 


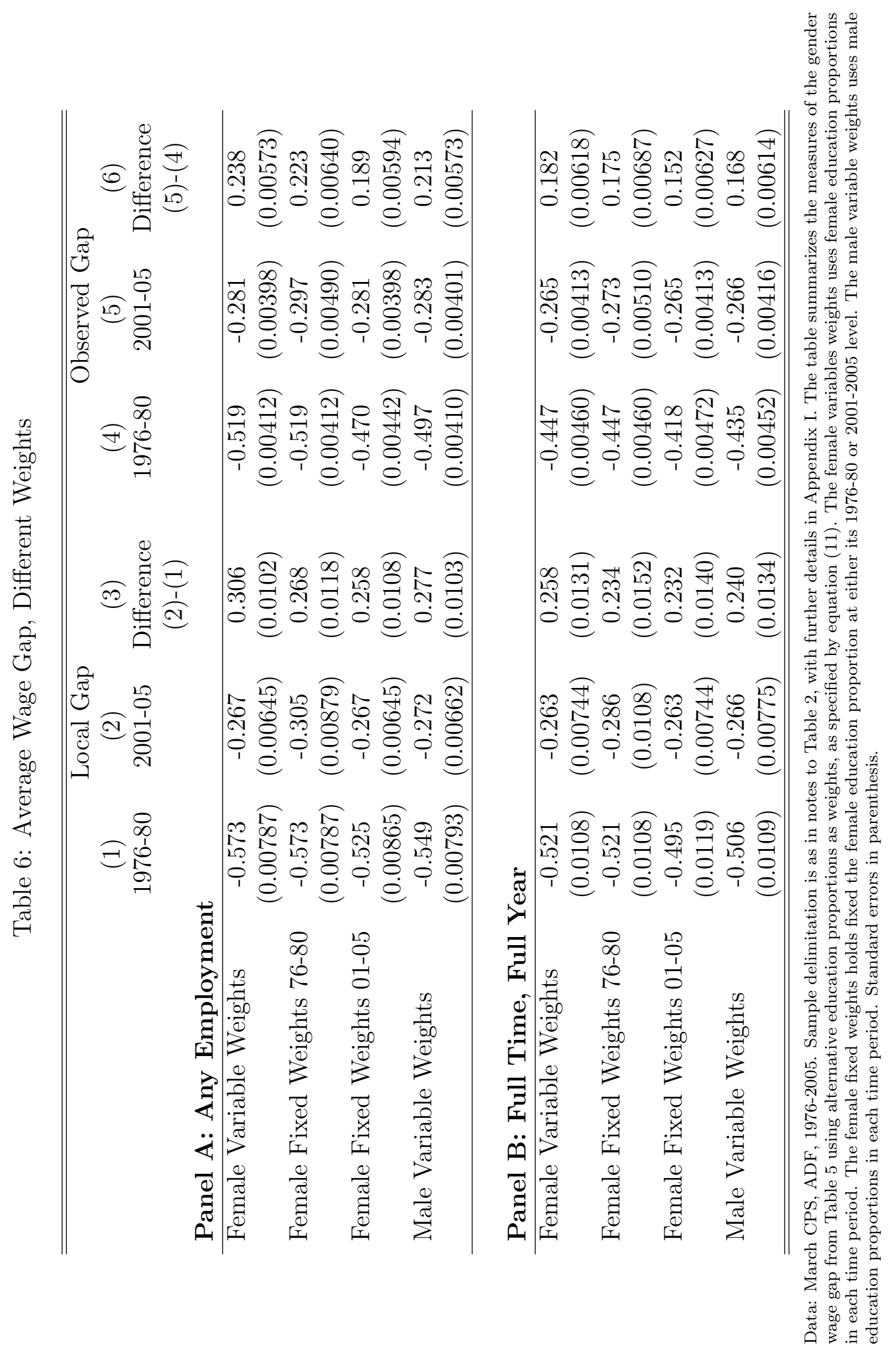




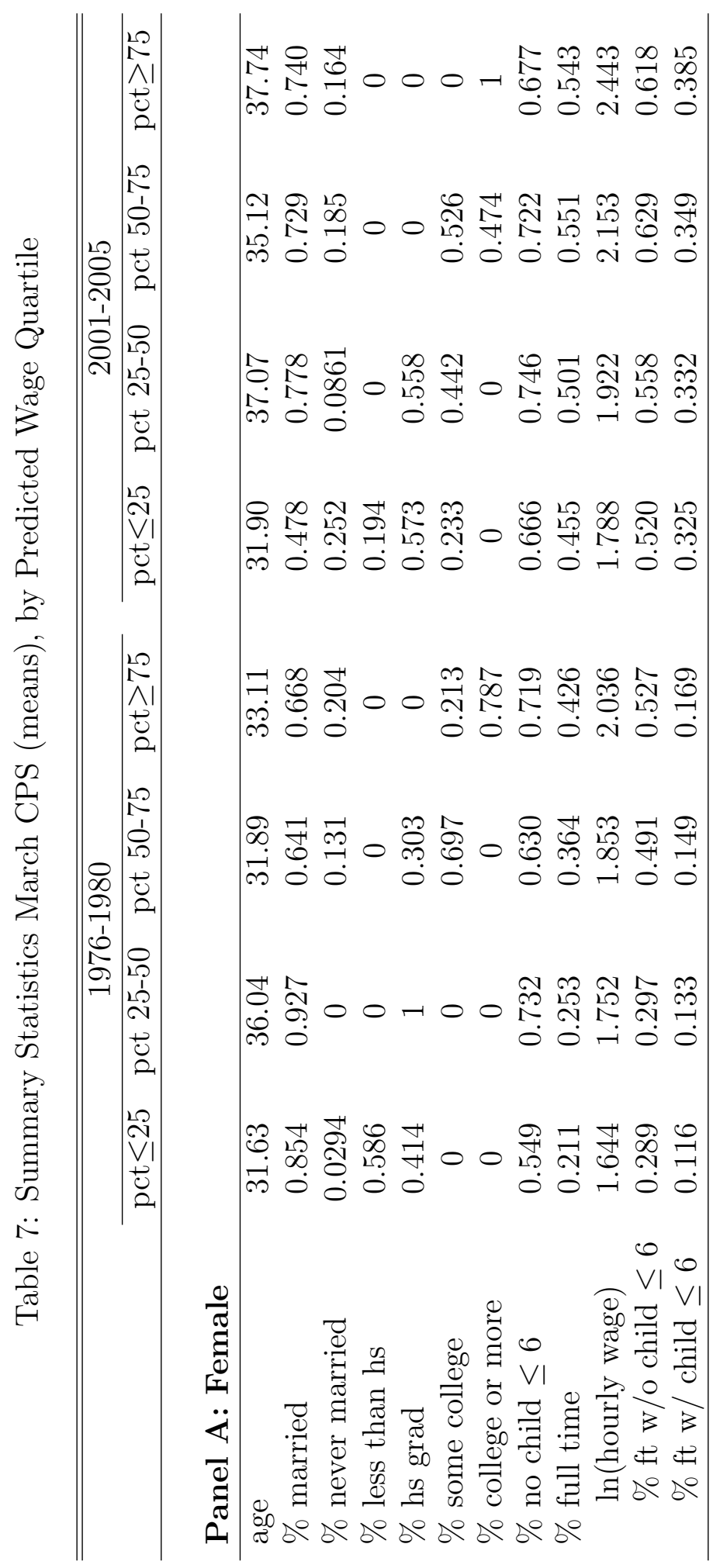

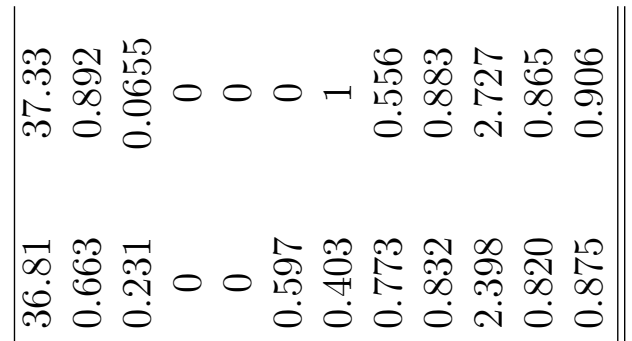

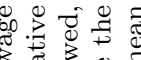

क

政

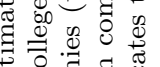

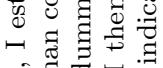

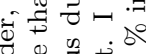

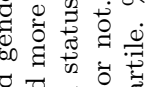

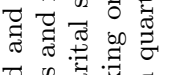

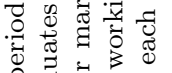

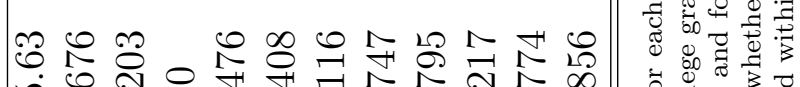

内人

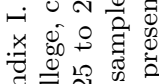

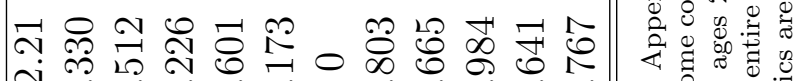

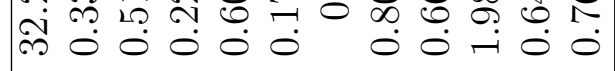

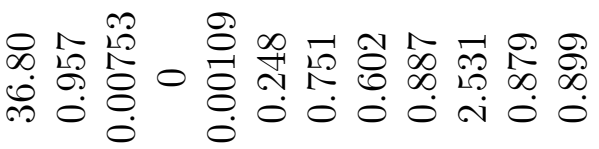

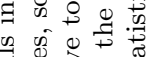

西

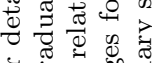

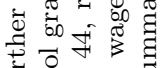

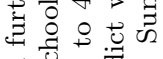

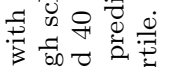

○ $0 \stackrel{\infty}{4} 010-41010$ No

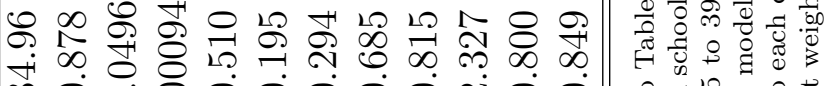

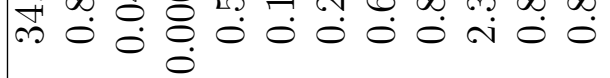

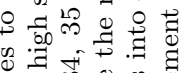

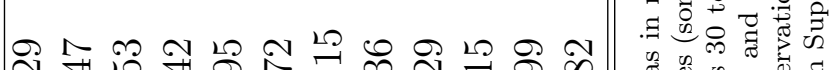

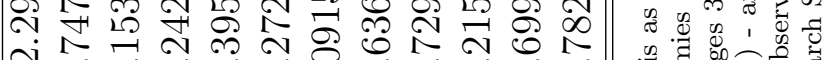
๙ิ

舟

$\infty$ 䒹 吾

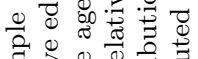

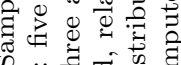

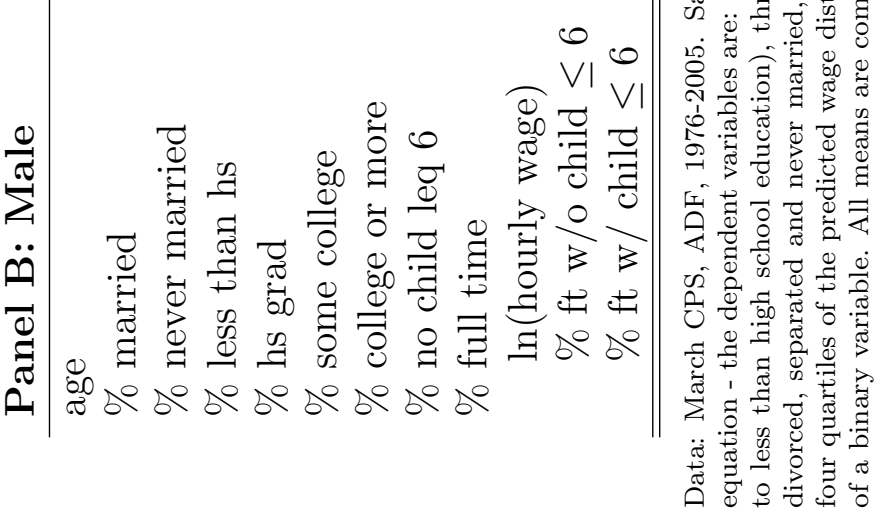


Table 8: March CPS Panel, Yearly Changes in the Gender Wage Gap

\begin{tabular}{|c|c|c|c|c|c|c|}
\hline \multirow[b]{3}{*}{$t=$} & \multicolumn{3}{|c|}{ Any Employment } & \multicolumn{3}{|c|}{ Full Time } \\
\hline & (1) & $(2)$ & $(3)$ & (4) & $(5)$ & (6) \\
\hline & $\mathrm{N}$ & $\delta_{3 t}$ & s.e. & $\mathrm{N}$ & $\delta_{3 t}$ & s.e. \\
\hline 1979 & 5963 & 0.013 & $(0.022)$ & 3703 & 0.005 & $(0.023)$ \\
\hline 1980 & 7805 & 0.021 & $(0.020)$ & 4821 & 0.027 & $(0.019)$ \\
\hline 1981 & 6872 & 0.022 & $(0.022)$ & 4212 & 0.002 & $(0.024)$ \\
\hline 1982 & 7007 & 0.008 & $(0.021)$ & 4187 & 0.009 & $(0.022)$ \\
\hline 1983 & 6942 & 0.017 & $(0.023)$ & 4168 & -0.000 & $(0.029)$ \\
\hline 1984 & 6915 & 0.012 & $(0.022)$ & 4336 & 0.001 & $(0.024)$ \\
\hline 1986 & 7204 & 0.010 & $(0.022)$ & 4611 & 0.028 & $(0.023)$ \\
\hline 1987 & 7240 & 0.011 & $(0.022)$ & 4720 & 0.005 & $(0.023)$ \\
\hline 1988 & 7577 & -0.009 & $(0.020)$ & 5015 & 0.012 & $(0.021)$ \\
\hline 1989 & 9067 & -0.025 & $(0.020)$ & 5914 & 0.000 & $(0.020)$ \\
\hline 1990 & 9527 & 0.019 & $(0.018)$ & 6189 & 0.024 & $(0.019)$ \\
\hline 1991 & 9376 & -0.009 & $(0.018)$ & 6060 & 0.003 & $(0.019)$ \\
\hline 1992 & 9061 & -0.018 & $(0.019)$ & 5891 & 0.006 & $(0.020)$ \\
\hline 1993 & 6751 & 0.008 & $(0.023)$ & 4405 & 0.004 & $(0.024)$ \\
\hline 1994 & 5809 & 0.013 & $(0.024)$ & 3857 & $0.048^{*}$ & $(0.028)$ \\
\hline 1996 & 7664 & 0.003 & $(0.021)$ & 5166 & 0.003 & $(0.022)$ \\
\hline 1997 & 7231 & -0.018 & $(0.022)$ & 4923 & -0.018 & $(0.023)$ \\
\hline 1998 & 7178 & -0.006 & $(0.022)$ & 4964 & 0.010 & $(0.023)$ \\
\hline 1999 & 7003 & -0.007 & $(0.022)$ & 4920 & -0.035 & $(0.024)$ \\
\hline 2000 & 6559 & 0.014 & $(0.023)$ & 4669 & 0.025 & $(0.024)$ \\
\hline 2001 & 6262 & -0.011 & $(0.024)$ & 4367 & 0.016 & $(0.027)$ \\
\hline 2002 & 7419 & -0.036 & $(0.024)$ & 5184 & -0.031 & $(0.027)$ \\
\hline 2003 & 7075 & -0.007 & $(0.025)$ & 4850 & -0.019 & $(0.026)$ \\
\hline \multirow[t]{3}{*}{2004} & 6151 & -0.034 & $(0.027)$ & 4296 & -0.036 & $(0.029)$ \\
\hline & & $(7)$ & (8) & & (9) & (10) \\
\hline & & coeff. & s.e. & & coeff. & s.e. \\
\hline Gap in $1979\left(\delta_{1 t=1997}\right)$ & & $-0.519^{* * *}$ & $(0.015)$ & & $-0.416^{* * *}$ & $(0.016)$ \\
\hline Gap in $2002\left(\delta_{1 t=2002}\right)$ & & $-0.247^{* * *}$ & $(0.017)$ & & $-0.219^{* * *}$ & $(0.017)$ \\
\hline Gap in $2004\left(\delta_{1 t=2004}\right)$ & & $-0.232^{* * *}$ & $(0.019)$ & & $-0.209 * * *$ & $(0.020)$ \\
\hline Gap Change 2004- & & $0.287 * * *$ & $(0.025)$ & & $0.206^{* * *}$ & $(0.026)$ \\
\hline \multicolumn{7}{|l|}{1979} \\
\hline Implied by $\sum_{t^{a}} \delta_{3 t}$ & & 0.025 & $(0.104)$ & & 0.125 & $(0.112)$ \\
\hline Implied by $\sum_{t^{b}} \delta_{3 t}$ & & 0.050 & $(0.119)$ & & 0.173 & $(0.129)$ \\
\hline Gap Change 2002- & & $0.271^{* * *}$ & $(0.022)$ & & $0.197^{* * *}$ & $(0.023)$ \\
\hline \multicolumn{7}{|l|}{1979} \\
\hline Implied by $\sum_{t^{c}} \delta_{3 t}$ & & 0.067 & $(0.099)$ & & $0.174^{*}$ & $(0.105)$ \\
\hline Implied by $\bar{\sum}_{t^{d}} \delta_{3 t}$ & & 0.093 & $(0.114)$ & & $0.223^{*}$ & $(0.123)$ \\
\hline
\end{tabular}

Data: March CPS, ADF, 1979-2005. Sample delimitation is as in notes to Table 2, with further details in Appendix I. Each line in the table refers to a two period matched sample between 1979 and 2005, where t correspond to the matched sample between $\mathrm{t}$ and $\mathrm{t}+1$. The matching variables are the household ID, the household number, the line number and the month in sample, as described in Madrian and Lefgren [1999]. Neither March 1984 and March 1985, nor March 1994 and March 1995, can be merged because of revisions in household identifiers. The match rate ranges from $30 \%$ to $57 \%$. For each matched sample, I estimate the change in the gender wage gap between men and women that are employed in the two subsequent periods of the data, as described by equation (12). $\mathrm{N}$ refers to the number of individuals in each period of the panel, $\delta_{3 t}$ to the change in the gender wage gap, and s.e. is the standard error of the estimator. $t^{a}$ : indexes years 1979 to 2003 , except 1985 and 1995 , which are the years the CPS data cannot be matched. $t^{b}$ : same as $t^{a}$, but double counting years 1984 and $1994 . t^{c}$ : indexes years 1979 to 2001, except 1985 and 1995. $t^{d}$ : same as $t^{c}$, but double counting years 1984 and 1994. *** denotes statistical significance at the $1 \%$ level. 


\section{Figure 1: Simulated Data, Distribution of Wages}

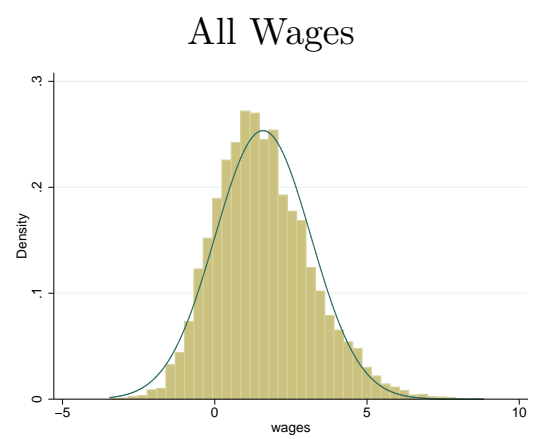

All Wages, type N

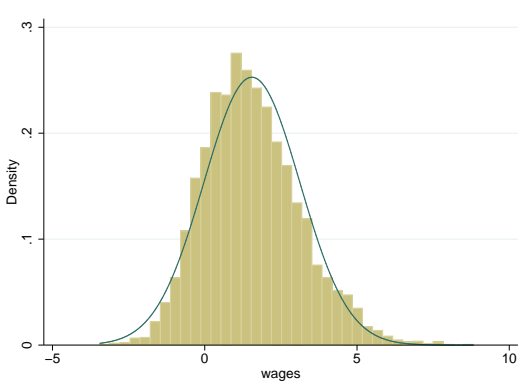

Wages of Employed

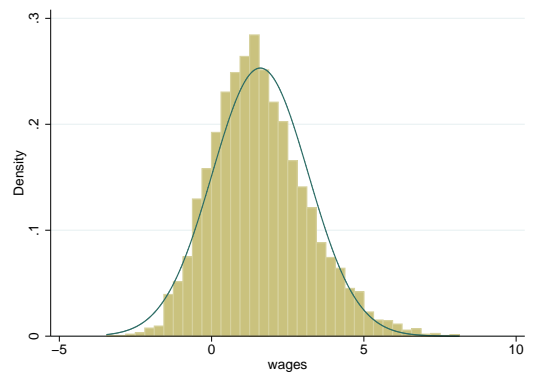

All Wages, type P

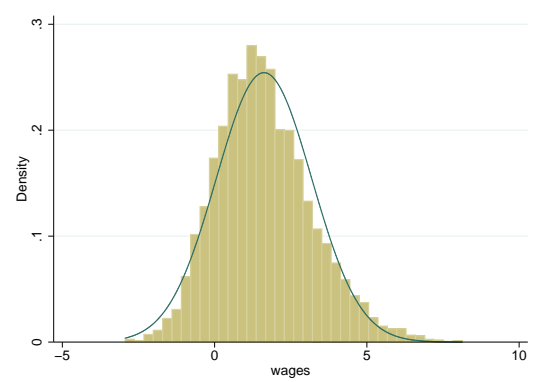

Data: Distribution of wages in one dataset with 10,000 observations generated by the model in equations (4) to (6).

Figure 2: Gender Wage Gap, Local vs Observed (Uncorrected) vs Parametric

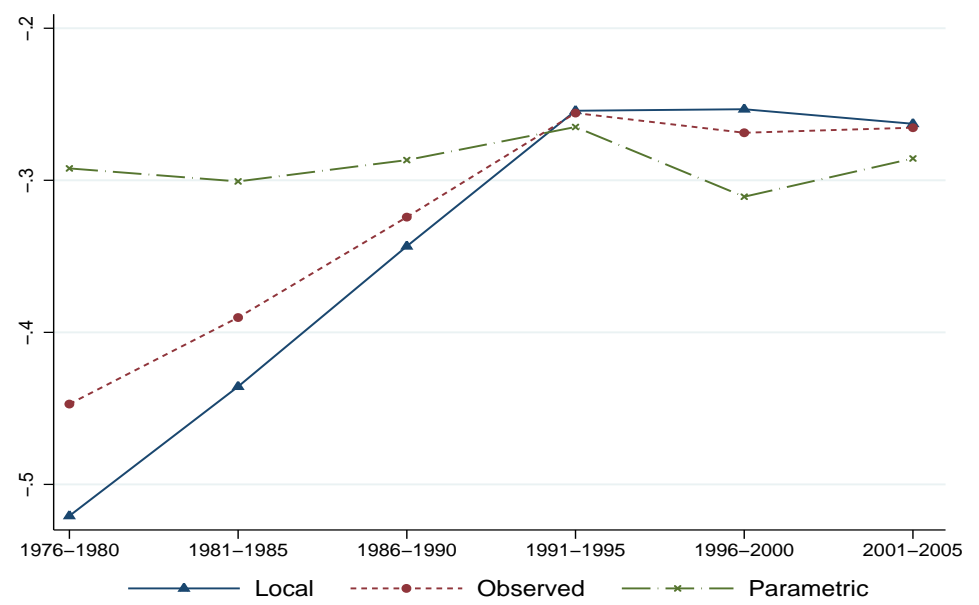

Data: March CPS, ADF, 1976-2005. Sample delimitation is as in notes to Table 2, with further details in Appendix I. The figure plots the gender wage gap (female minus male wages) in log wage points. The local gap averages estimates of $(9), \hat{\beta}_{1 x t}+\hat{\beta}_{2 x t}$, using female education proportions in each time period. The observed (uncorrected) and parametric gaps average estimates of (A.1) and (A.3), $\hat{\kappa}_{1 x t}$ and $\hat{\theta}_{1 x t}$, using the same weights. In all estimates, employment is defined by full time full year work. The instrument used to estimate the local and parametric gaps is an indicator for the presence of a child younger than six years old. 


\section{Figure 3: Local Gender Wage Gap, by Percentiles of Predicted Wage}

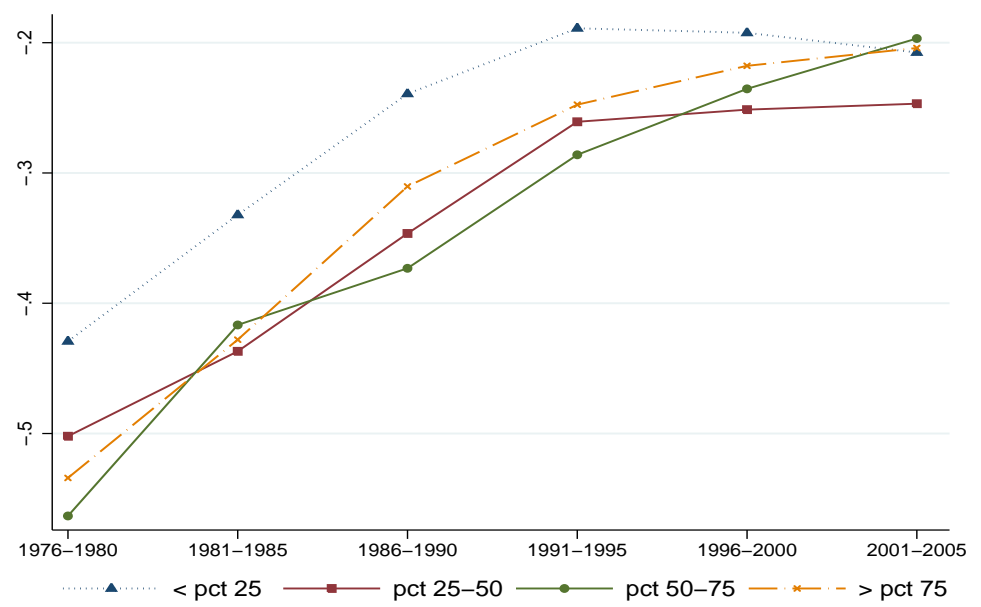

Data: March CPS, ADF, 1976-2005. Sample delimitation is as in notes to Table 2, with further details in Appendix I. The figure plots the local gender wage gap (female minus male wages) in log wage points, by quartiles of predicted wages. The quartiles are generated as following: for each period and gender, I estimate a wage equation - the dependent variables are: five education dummies (some high school, high school graduates, some college, college graduates and more than college, relative to less than high school education), three age dummies (ages 30 to 34, 35 to 39 and 40 to 44, relative to ages 25 to 29) and four marital status dummies (widowed, divorced, separated and never married, relative to married) - and use the model to predict wages for the entire sample, whether working or not; I then compute the four quartiles of the predicted wage distribution and sort observations into each quartile. The local gender gap is estimated between men and women that have the same rank in its own predicted wage distribution. I take $X$ to be the four quartiles and estimate (9). In all estimates, employment is defined by full time full year work. The instrument used to estimate the local gaps is an indicator for the presence of a child younger than six years old. The lines stratify results by the four quartiles of the predicted wage distribution.

\section{Figure 4: Observed Gender Wage Gap, by Percentiles of Predicted Wage}

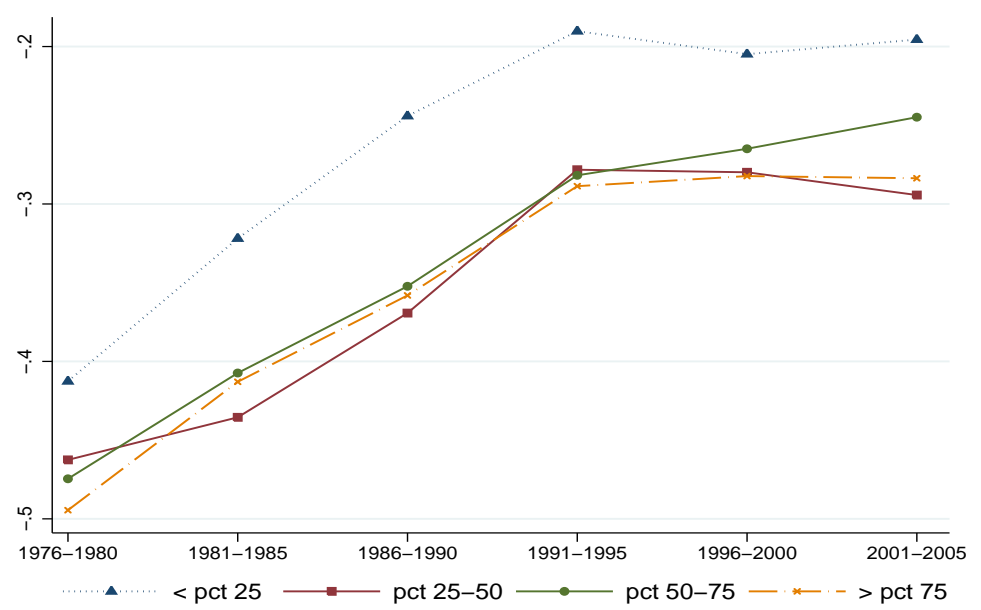

Data: March CPS, ADF, 1976-2005. Sample delimitation is as in notes to Table 2, with further details in Appendix I. The figure plots the observed (uncorrected) gender wage gap in log wage points, by quartiles of predicted wages. The quartiles are generated as in notes to Figure 3. The observed (uncorrected) gap is estimated by the coefficient on the female dummy in a log wage regression, as outlined in Appendix II. In all estimates, employment is defined by full time full year work. The lines stratify results by the four quartiles of the predicted wage distribution. 


\section{Figure 5: Local Gender Wage Gap, Female and Male "Always Employed"}

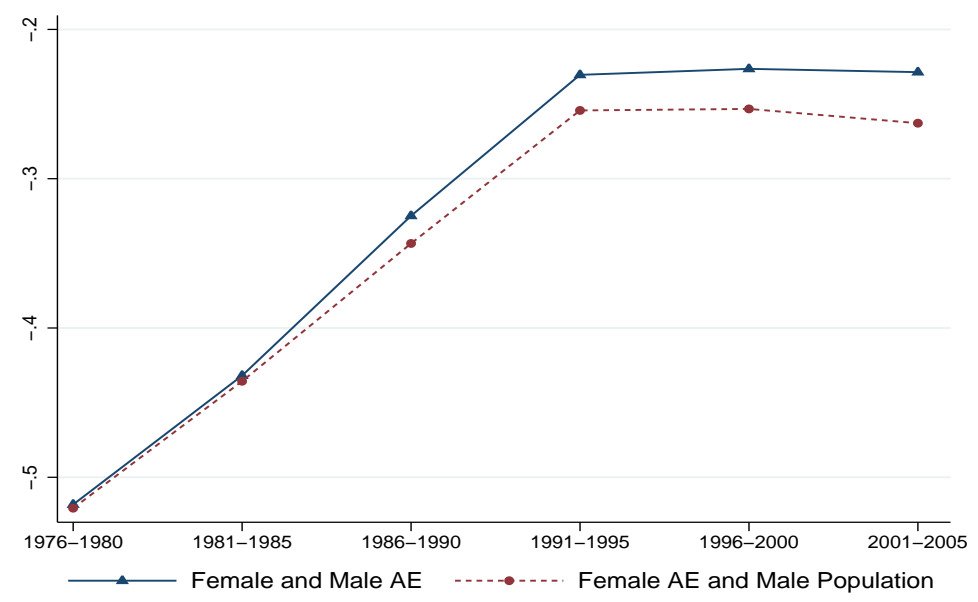

Data: March CPS, ADF, 1976-2005. Sample delimitation is as in notes to Table 2, with further details in Appendix I. The figure plots the local gender wage gaps (female minus male wages) in log wage points. The "Female and Male AE" line averages estimates of (10), $\hat{\beta}_{1 x t}+\hat{\beta}_{2 x t}$, using female education proportions in each time period. The "Female AE and Male Population" line averages estimates of (9), $\hat{\beta}_{1 x t}+\hat{\beta}_{2 x t}$, using the same weights. Employment is defined by full time full year work in both lines. The instrument used to estimate the local gaps is an indicator for the presence of a child younger than six years old.

\section{Figure 6: Local Gender Wage Gap, by Age of Young Child}

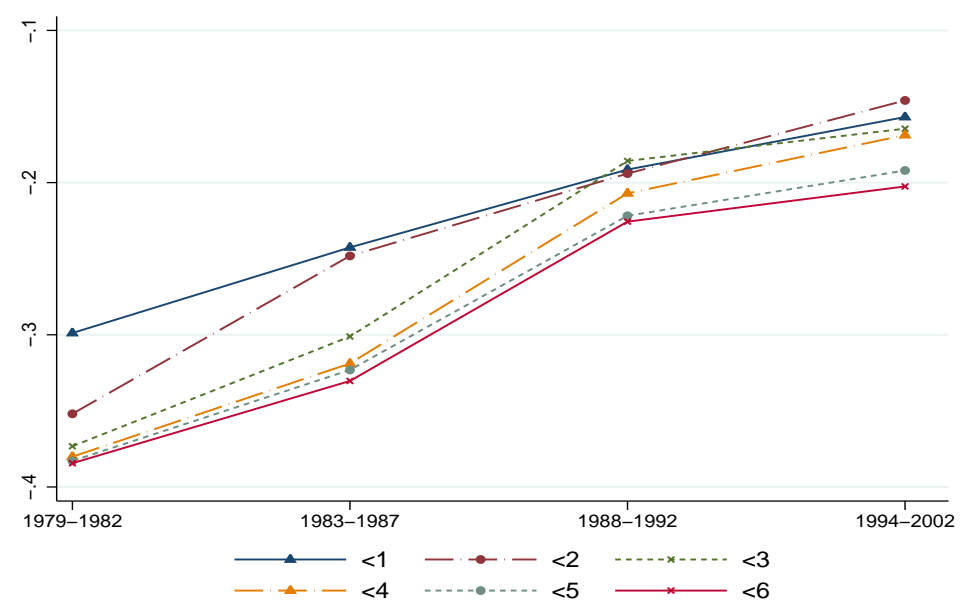

Data: June CPS, 1979-2002. Sample delimitation is as in notes to Table 3, with further details in Appendix I. The figure plots the local gender wage gap (female minus male wages) in log wage points. The local gap averages estimates of $(9), \hat{\beta}_{1 x t}+\hat{\beta}_{2 x t}$, using female education proportions in each time period. In all estimates, employment is defined by full time full year work. Lines differ with respect to instrument used in estimation: child younger than $j$, with $j \in\{1, \ldots, 6\}$. 


\section{Figure A.I: Bounds on Median Wage Gap, US}
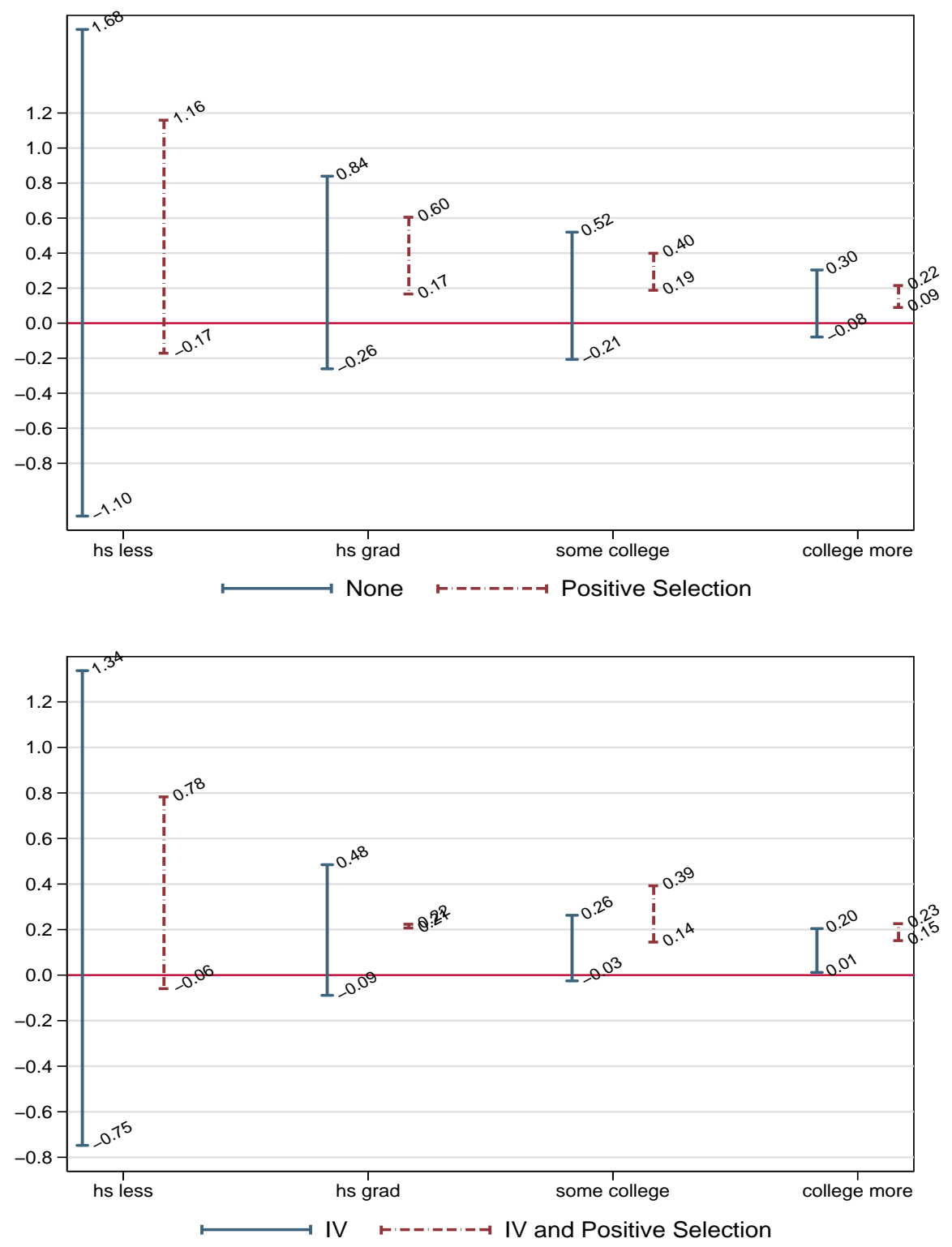

Data: March CPS, ADF, 1976-2005. Sample delimitation is as in notes to Table 2, with further details in Appendix I. The figure plots changes in the gender median wage differential from 1976 to 2005, as specified in (A.10) and (A.11), stratified by education groups. "None" denotes neither the use of an exclusion restriction nor the use of a selection assumption when estimating the bounds. "Positive Selection" denotes the use of a positive selection assumption for all periods and all genders. "IV" denotes the use of an exclusion restriction, a binary indicator for the presence of a child younger than six, in the bounds for the median wages of women. "IV and Positive Selection" combines the exclusion restriction for women with a positive selection assumption for both men and women. The bounds under "IV and Positive Selection" for individuals with some college or more cross. 